\title{
Sectores acuíferos en la MASb 041.001 Sierra de Altomira. Definición a partir de criterios estructurales e hidrodinámicos
}

\author{
José Antonio Domínguez Sánchez (1), Jesús del PozoTejado ${ }^{(2)}$ y Miguel Mejías Moreno (2) \\ (1) Instituto Geológico y Minero de España, Unidad de Valencia \\ (2) Instituto Geológico y Minero de España, Ríos Rosas 23, 28003 Madrid \\ ja.dominguez@igme.es; j.delpozo@igme.es; m.mejias@igme.es
}

\begin{abstract}
RESUMEN
Las actividades desarrolladas en el marco del Convenio Específico de Colaboración que se suscribió en julio de 2012 entre el Instituto Geológico y Minero de España (IGME) y la Comunidad de Usuarios de Aguas Subterráneas de la Sierra de Altomira, han ampliado el ya extenso conocimiento hidrogeológico de la masa de agua subterránea (MASb) Sierra de Altomira. Se ha establecido su balance hídrico con consumos actualizados y unas entradas al sistema muy ajustadas. También, como ya se indica en estudios previos, se ha constatado la complejidad hidrogeológica de la MASb y la posibilidad de que se encuentre compartimentada en acuíferos independientes. Por un lado, la revisión de datos históricos y actuales referentes a piezometría y aforos, ha permitido definir distintos sectores acuíferos en la MASb en función de su hidrodinámica. Por otro, un profundo análisis del origen y formación de las estructuras sedimentarias que hoy constituyen los niveles permeables, ha sido la base de una sectorización tectónica, a escala regional y local, con evidentes repercusiones hidrogeológicas. El presente artículo contrasta ambas compartimentaciones, analiza su compatibilidad y las ventajas que, para la eficaz gestión de los recursos hídricos subterráneos de la MASb, supone la división de la misma en ámbitos hidrogeológicos menores. Con este objetivo, se establecen finalmente cuatro sectores acuíferos independientes (sector acuífero de Uclés; sector acuífero de Carrascosa del Campo; sector acuífero de Mota del Cuervo y sector acuífero de Villar de Cañas) cuyos balances hídricos pueden ser ajustados con mayor precisión.
\end{abstract}

Palabras clave: Acuíferos, geología estructural, hidrodinámica, hidrogeología, Sierra de Altomira.

\section{Aquifer sectors within the GWB 041.001 Sierra de Altomira. Definition from structural and hydrodynamic criteria}

\begin{abstract}
The activities developed within the Specific Collaboration Agreement that was signed in July 2012 between the Spanish Geological Survey (IGME) and the Community of Groundwater Users of the Sierra de Altomira, have expanded the already extensive hydrogeological knowledge of the Sierra de Altomira groundwater body (GWB). Its water balance has been established with updated consumption and very tight system inputs. As has already been indicated in previous studies, the hydrogeological complexity of the GWB has been verified and the real possibility that it is compartmentalized into independent aquifers. On the one hand, the review of historical and current data related to piezometry and foronomy has allowed the definition of the different aquifer sectors based on their hydrodynamics. On the other hand, an in-depth analysis of the origin and formation of the sedimentary structures that today constitute the permeable levels of the GWB, has been the basis of a tectonic sectorization, on a regional and local scale, with evident hydrogeological repercussions. This article contrasts both sub-divisions and analyzes their compatibility and the advantages that, for the effective management of the underground water resources of the GWB, involve its division into smaller hydrogeological areas. With this objective, four aquifer sectors have finally been established (the Uclés aquifer sector; the Carrascosa del Campo aquifer sector; the Mota del Cuervo aquifer sector and the Villar de Cañas aquifer sector) where the water balances can be adjusted with greater precision.
\end{abstract}

Keywords: aquifers; hydrodynamic; hydrogeology; Sierra de Altomira; structural geology 


\section{Introducción geográfica e hidrogeológica. Objetivos}

La masa de agua subterránea (en adelante MASb) Sierra de Altomira pertenece a la comunidad autónoma de Castilla-La Mancha. De sus $2.575 \mathrm{~km}^{2}$, el $90 \%$ corresponden a la provincia de Cuenca, y en mucha menor proporción, a Toledo (7\%) y Ciudad Real (3\%).

Esta MASb se sitúa en la cuenca alta del río Guadiana. En sentido estricto, queda limitada al norte por la divisoria hidrográfica con la Demarcación del Tajo; el límite NE viene definido por el contacto con la MASb 041.002 La Obispalía; el límite oriental lo constituye la divisoria hidrográfica de las cuencas del Guadiana y Júcar; al SE limita con la MASb 041.005 Rus-Valdelobos; al sur con la MASb 041.006 Mancha Occidental II y, finalmente, en el límite $\mathrm{O}$ se sitúan las MASb 041.003 Lillo-Quintanar y 041.004 Consuegra-Villacañas (figura 1).

La cuenca alta del río Guadiana puede considerarse, a nivel hidrogeológico, como una unidad en sí, aten- diendo a las transferencias laterales de agua subterránea que se producen entre las distintas MASb que la integran (Martínez et al., 2011; Mejías, 2014). No obstante, pese a los diversos estudios realizados han existido, y aún se mantienen, incertidumbres sobre los límites reales de los acuíferos presentes en esta zona. Ello ha provocado modificaciones a lo largo del tiempo en la delimitación territorial y marco administrativo aplicado a las aguas subterráneas del entorno de la Sierra de Altomira. En 1979 el Instituto Geológico y Minero de España (IGME, 1979) estableció el Sistema Acuífero (S.A.) $n^{\circ} 19$ - Sierra de Altomira. Posteriormente, se delimitan en el territorio peninsular y las islas Baleares las Unidades Hidrogeológicas (U.H.), entre ellas la Unidad Hidrogeológica 04.01 Sierra de Altomira, dentro de la cuenca Hidrográfica del Guadiana (IGME-MOPU, 1988).

Finalmente, con la aplicación de la transposición a la legislación española de la Directiva Marco del Agua (DMA) (2000/60/CE), se establece una nueva meto-

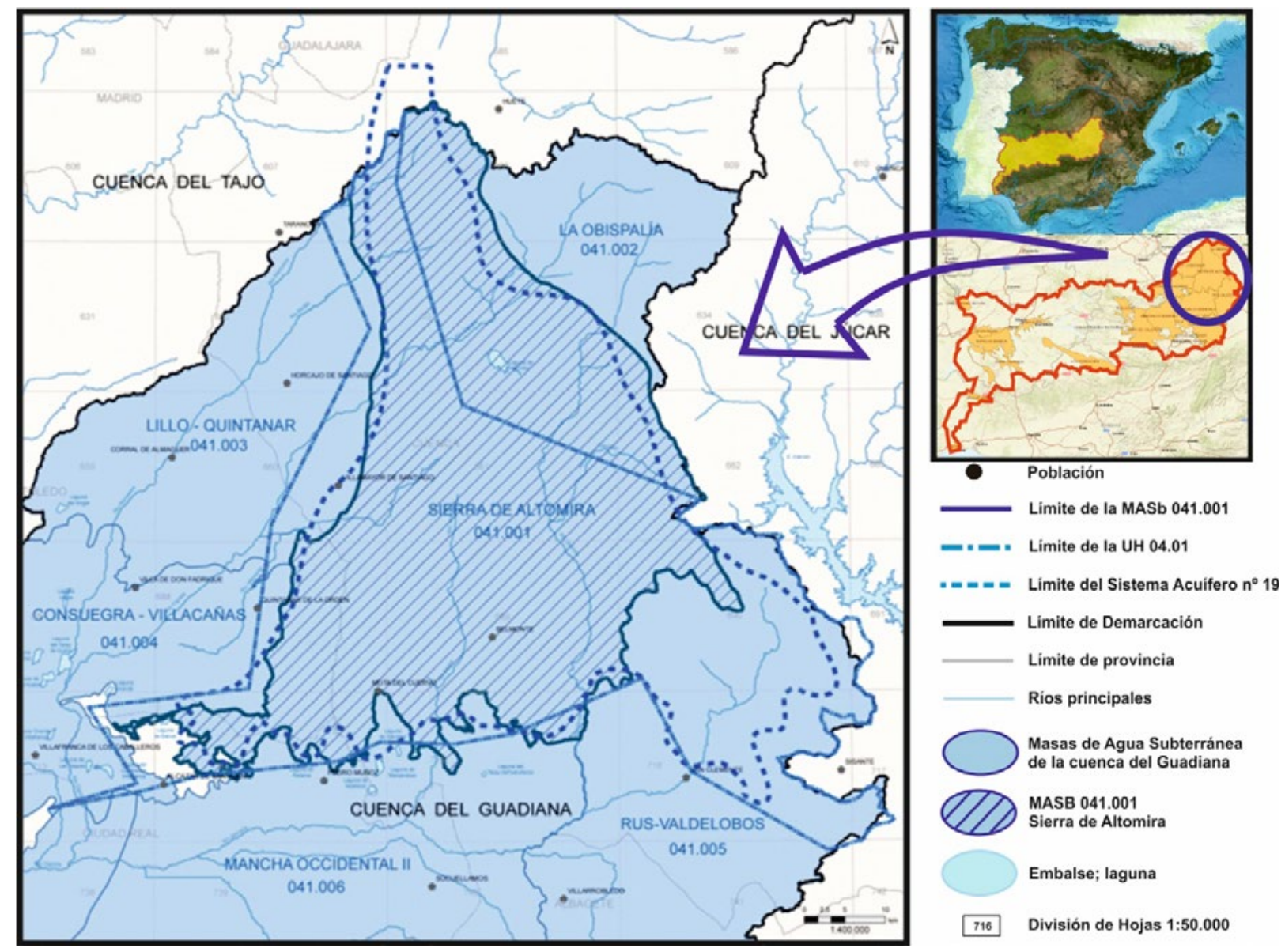

Figura 1. Localización geográfica de la MASb Sierra de Altomira (Demarcación Hidrográfica del Guadiana). Anteriores divisiones administrativas. Modificado de Domínguez et al., 2016.

Figure 1. Geographic location of the Sierra de Altomira GWB (Guadiana basin). Previous administrative divisions. Modified from Domínguez et al., 2016. 
dología con el objeto de lograr la protección de las aguas en los estados miembros de la Unión Europea y se incorpora una nueva figura de gestión hidrológica, la conocida como Masa de Agua Subterránea (MASb). Como consecuencia se definen estas MASb en el territorio nacional, en los respectivos Planes $\mathrm{Hi}$ drológicos de Cuenca, entre ellas la MASb Sierra de Altomira 041.001, definida en el Plan Hidrológico de la parte española de la Demarcación Hidrográfica del Guadiana, del ciclo de planificación 2009-2015, aprobado en el RD 354/2013 (figura 1).

Las implicaciones socioeconómicas son evidentes y con frecuencia negativas, puesto que se aplican modelos de gestión de los recursos hídricos subterráneos a entornos espaciales deficientemente conocidos, tanto en su extensión real, como en sus recursos disponibles.

Un ejemplo reciente es la diferencia entre la recarga natural de la MASb del Plan Hidrológico de la parte española de la Demarcación Hidrográfica del Guadiana (2009-2015) calculada en 107 hm³/año y los 115 hm³/año que se estiman en el balance de Mejías et al. de 2014.

En los últimos años el Instituto Geológico y Minero de España (IGME) ha suscrito diversos convenios de colaboración con otros organismos públicos como la Confederación Hidrográfica del Guadiana (2009) o la Excma. Diputación de Cuenca (2011) y entidades privadas, como la Comunidad de Usuarios de Aguas Subterráneas de la Sierra de Altomira (2012 y 2016), en los que se han desarrollado trabajos con el fin de ampliar, aún más, el conocimiento hidrogeológico de la MASb Sierra de Altomira. Tales estudios permiten plantear nuevas propuestas de gestión de los recursos hídricos subterráneos basadas en el análisis de ámbitos hidrogeológicos menores. Siguiendo esta línea, el objetivo fundamental del presente trabajo es dividir la MASb 041.001 Sierra de Altomira en varios sectores acuíferos a partir de criterios hidrodinámicos y tectónicos que permitan estimaciones más ajustadas del balance hídrico como paso previo para alcanzar una gestión eficiente de los recursos hídricos subterráneos (Domínguez et al., 2014), no tanto el caracterizar la totalidad de acuíferos de la misma, labor que requiere estudios mucho más detallados.

\section{Metodología y potencial de los datos analizados}

La MASb Sierra de Altomira se encuentra en un contexto hidrogeológico y estructural complejo que condiciona claramente la hidrodinámica subterránea. Existen barreras hidrogeológicas y estructurales internas, tanto en la horizontal como en la vertical, que compartimentan la MASb en sectores acuíferos, en muchos casos totalmente independientes, lo que ha motivado la definición, por parte de distintos autores, de diversas subunidades acuíferas desconectadas y modelos hidrogeológicos conceptuales de funcionamiento distintos (Sánchez, 1973; Muñoz, 1997; Díaz, J.A. y Martínez, M. 2009; Díaz et al., 2011; Martínez y Díaz, 2013).

La mejora de la gestión de los recursos hídricos a partir de la división de esta zona en diversos sectores acuíferos aplicando criterios hidrogeológicos ya ha sido abordada, entre otros, por Martínez y Díaz (2013). En su estudio se incluye el criterio de accesibilidad al recurso para delimitar, mediante poligonales, una serie de subsistemas acuíferos jurásicos (SAJ) y subsistemas acuíferos cretácicos (SAC) en las MASb (041.001) Sierra de Altomira y (041.005) Rus-Valdelobos.

El presente artículo se centra exclusivamente en la MASb Sierra de Altomira y se basa fundamentalmente en el análisis y correlación de los resultados de los estudios hidrogeológicos realizados en la MASb en los últimos años. Por un lado, se establece una sectorización hidrodinámica a partir de trazar unos límites internos en la MASb según los datos piezométricos (Galindo et al., 2012; Domínguez et al., 2016 y 2018a); por otro, se alcanza una sectorización tectónica a partir de dividir la MASb en sus Unidades Hidrogeológicas Básicas (en adelante UHB) que se definen como las unidades estructurales mínimas divisibles con funcionamiento hidrogeológico individualizado (del Pozo et al., 2019).

Las sectorizaciones básicas así obtenidas (hidrodinámica y tectónica) se han cotejado entre sí, comprobando sus similitudes y valorando su compatibilidad. También se han contrastado con los resultados de otros estudios de carácter hidrogeológico realizados en el entorno de la MASb Sierra de Altomira como son las campañas foronómicas de los principales cursos fluviales de la MASb o el análisis de las relaciones río-acuífero (Murillo et al., 2010; Domínguez et al., 2018b).

Esta metodología, por tanto, establece dos líneas de trabajo esenciales: la primera se centra en la definición, análisis y compatibilidad de las dos sectorizaciones básicas $y$, la segunda, en sustentar las mismas con los resultados de otros estudios hidrológicos e hidrogeológicos relacionados.

Así, en una primera fase se aborda el estudio y correlación de los siguientes apartados:

- Estratigrafía: a partir de la serie estratigráfica tipo de la MASb se definen los distintos niveles permeables, identificando los tramos acuíferos principales y desestimando, para este estudio, aquellos de carácter local. Así, por sus características e importancia, se han considerado como acuíferos representativos de la MASb Sierra de Altomira únicamente los niveles carbonatados 
del Jurásico (Lías-Dogger) y los del Cretácico (Cenomaniense-Campaniense). Se asume que estos están hidrogeológicamente desconectados, por lo que no habría conexión efectiva entre ambos, pese a que en determinadas zonas la tectónica pueda ponerlos en contacto.

- Hidrodinámica: una vez definidos los niveles acuíferos en la vertical, se ha diseñado una red de observación piezométrica que ha contado con un total de 44 puntos, pertenecientes tanto a la red oficial de la Cuenca Hidrográfica del Guadiana como a sondeos y pozos particulares o de gestión municipal. De estos, únicamente se tienen en cuenta los 12 que puntos captan el acuífero carbonatado jurásico (tabla 1) y los 20 puntos del acuífero carbonatado cretácico (tabla 2). Pese a que en algunas áreas de la MASb queda un número reducido de puntos de control de la piezometría, lo que dificulta la interpretación hidrodinámica, en otras, la densidad de puntos de observación permite trazar límites o barreras hidráulicas al flujo subterráneo (para cada nivel acuífero) y diferenciar sectores con distinto comportamiento hidrodinámico.

- Tectónica: la disposición actual de los materiales que constituyen la MASb es el fruto de una evolución estructural cuyo análisis a diferente escala, desde la regional hasta una escala local, permite definir los mínimos bloques tectónicos con repercusión hidrogeológica estructuralmente independientes: las denominadas UHB. Los márgenes oriental y occidental de estos bloques quedan delimitados por estructuras de deformación longitudinales, fallas, cabalgamientos y pliegues, con orientación norte-sur que actúan como barreras al flujo subterráneo. Mientras que sus márgenes septentrional y meridional coinciden con zonas de transferencia tectónica, que cortan a las estructuras anteriores transversalmente, y permiten la conexión hidráulica entre las formaciones permeables de diferentes UHB, por lo que actúan como zonas de transferencia hidrogeológica (del Pozo et al., 2019).

La segunda línea de trabajo aborda los siguientes campos de análisis:

- Estudio de la red hidrográfica: se analiza el trazado de los principales cauces de la MASb y se agrupan según la orientación de los mismos (tabla 5). Se parte de la idea de que la disposición de la red hidrográfica está íntimamente relacionada con la orientación de las principales estructuras tecto-sedimentarias, con las cuales se alinean o intersectan, y con las características físicas de los materiales sobre los que se encaja, es decir, su mayor o menor resistencia a la erosión.

- Estudio de la relación río-acuífero: a partir de los resultados del estudio de Domínguez et al. (2018 b) en el que se estableció una red de 26 secciones de aforo a lo largo de los principales cursos fluviales (tabla 6 y figura 10), se aborda la posible correlación entre las sectorizaciones básicas y los diferentes tipos de relación río-acuífero, tanto de un mismo cauce como de cursos de agua próximos. La hipótesis considera que, en un medio no influenciado, los cambios de relación río-acuífero, entendida como transferencia de recursos entre el acuífero y el cauce, se deben a una variación en la posición de la superficie piezométrica, y que esta variación puede deberse a la presencia de una barrera hidrogeológica que modifica la hidrodinámica de un mismo acuífero o que separa acuíferos diferentes. En tal circunstancia un límite trazado a partir del cambio de la relación río-acuífero puede coincidir con un límite entre acuíferos distintos. Con esta premisa se han definido las relaciones río-acuífero en diferentes tramos de los principales cursos fluviales de la MASb y, consecuentemente, se han podido identificar posibles límites cuando cambia el tipo de relación. De igual manera, se ha considerado que puede existir un límite entre cauces contiguos que presentan relaciones río-acuífero distintas.

\section{Marco geológico}

La Sierra de Altomira se sitúa en la denominada Rama Castellano-Valenciana de la cordillera Ibérica (Guimerá, 2004) y se extiende a lo largo de más de $100 \mathrm{~km}$, con dirección N-S a NNO-SSE en su parte más meridional. Su límite occidental, con la Cuenca Terciaria de Madrid, se estructura mediante un cabalgamiento con un salto vertical de más de $1500 \mathrm{~m}$. Por el este, la Sierra de Altomira limita con la Cuenca de Loranca; esta a su vez es cabalgada en el este por la Sierra de Bascuñana. Ambas sierras consisten, básicamente, en sistemas imbricados de cabalgamientos de tipo "thin-skinned" (Sánchez, 1973; Muñoz, 1997) en los que la deformación afecta exclusivamente a la cobertera sedimentaria y no al basamento. La MASb, por tanto, se estructura a partir de un cinturón de pliegues y cabalgamientos mesozoico-terciarios, de marcada vergencia hacia el oeste, y de dirección general N-S, despegados del basamento hercínico y del tegumento triásico gracias al nivel de despegue que constituyen las arcillas de la facies Keuper (figura 2). 


\begin{tabular}{|c|c|c|c|c|c|c|c|c|c|c|c|c|}
\hline $\begin{array}{l}\bar{g} \\
\bar{g} \\
\bar{g} \\
\bar{g}\end{array}$ & 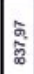 & 胥 & छ & & \multicolumn{8}{|c|}{ 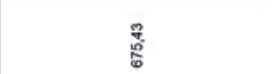 } \\
\hline $\begin{array}{l}\frac{a}{0} \\
\frac{\partial}{\Sigma}\end{array}$ & ప్ & 鹿 & 荵 & 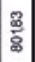 & & 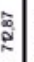 & 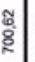 & 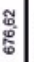 & 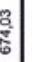 & 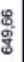 & 兽 & : \\
\hline$\frac{\frac{\circ}{\frac{E}{E}}}{\frac{\varepsilon}{\Sigma}}$ & 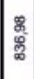 & $\begin{array}{l}\mathbf{D} \\
\mathbf{W} \\
\mathbf{w}\end{array}$ & 埕 & 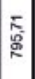 & : & $\begin{array}{l}\$ \\
\vdots \\
\vdots\end{array}$ & \begin{tabular}{l|}
0 \\
$\vdots$ \\
$\vdots$
\end{tabular} & 兽 & : & : & $\begin{array}{l}\text { 象 } \\
\text { 总 }\end{array}$ & 路 \\
\hline 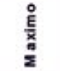 & 罾 & $\begin{array}{c}\mathbf{5} \\
\mathbf{w} \\
\mathbf{w}\end{array}$ & 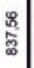 & 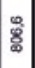 & ลี & $\begin{array}{l}0 \\
0 \\
0\end{array}$ & 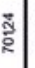 & \%ั. & 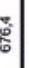 & $\begin{array}{l}8 \\
8 \\
8 \\
8\end{array}$ & $\begin{array}{l}\frac{\bar{\sigma}}{\mathrm{\sigma}} \\
\frac{\mathrm{m}}{\mathrm{w}}\end{array}$ & శ్ \\
\hline$\stackrel{\frac{\pi}{3}}{\vdots}$ & 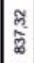 & 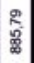 & & & & & ¿. & \$ి & 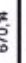 & 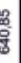 & 象 & \\
\hline 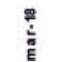 & 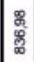 & 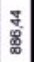 & & 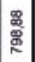 & & & $\begin{array}{l}0 \\
\vdots \\
\vdots\end{array}$ & 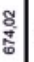 & $\overline{6}$ & 管 & $\begin{array}{l}\text { 禺 } \\
\text { : }\end{array}$ & \\
\hline 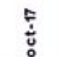 & 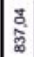 & 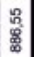 & & 拳 & & 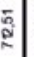 & 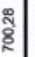 & ฐ్ & t్ & E. & : & \\
\hline 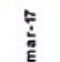 & 笱 & $\begin{array}{l}\mathbf{8} \\
\mathbf{D} \\
\mathbf{D} \\
\mathbf{D}\end{array}$ & & 商 & & 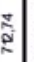 & 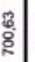 & 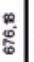 & \% & 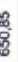 & 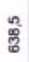 & \\
\hline$\frac{2}{\grave{u}}$ & 疍 & 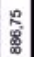 & & 总 & & $\begin{array}{c}\tilde{0} \\
\vdots \\
0\end{array}$ & 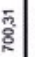 & 离 & 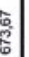 & 雃 & 禺 & \\
\hline 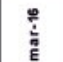 & $\stackrel{\infty}{\%}$ & & & 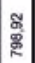 & & 总 & 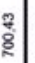 & ָิ & the & 薄 & 高 & \\
\hline ذِّ & 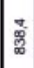 & 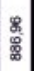 & 总 & 管 & & 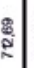 & $\begin{array}{l}\overline{5} \\
\vdots \\
\vdots\end{array}$ & 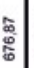 & 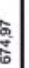 & $\frac{8}{8}$ & 惫 & \\
\hline 苋 & \% & 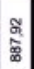 & 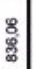 & 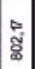 & స్ & 营 & $\begin{array}{l}\frac{9}{2} \\
\frac{2}{8}\end{array}$ & 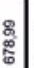 & 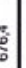 & 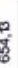 & 总 & \\
\hline 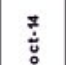 & $\begin{array}{l}\text { సิ } \\
\text { : }\end{array}$ & 茞 & 总 & $\mid \begin{array}{l}: \\
\vdots \\
\vdots \\
\vdots\end{array}$ & & $\begin{array}{l}\mathbb{Q} \\
0\end{array}$ & ๕. & 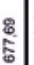 & $\frac{6}{6}$ & t. & : & \\
\hline 蛋 & & $\begin{array}{l}\text { b } \\
\vdots \\
\mathbf{m}\end{array}$ & 鼌 & 氛 & & 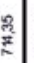 & 㤩 & 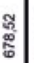 & 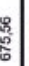 & 育 & 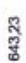 & \\
\hline 莣 & & & స్ఞ & $\begin{array}{l}\mathbf{0} \\
\vdots \\
\vdots \\
\vdots \\
\vdots\end{array}$ & & $\begin{array}{l}2 \\
z \\
z \\
z\end{array}$ & \$े & 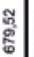 & $\begin{array}{r}\frac{\pi}{5} \\
\frac{5}{5}\end{array}$ & 8 & 产 & \\
\hline$\stackrel{2}{0}$ & & & 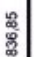 & 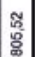 & & 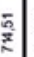 & ถึ & 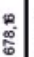 & $\frac{8}{6}$ & $\frac{1}{8}$ & ๕̊ & 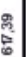 \\
\hline$\frac{\frac{2}{2}}{\frac{1}{3}}$ & & & 胗 & 芦 & & $\begin{array}{l}8 \\
8 \\
8\end{array}$ & $\bar{\Sigma}$ & : & $\begin{array}{l}0 \\
5 \\
5\end{array}$ & 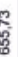 & 总 & : \\
\hline 号 & & & 㤐 & 怘 & 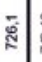 & 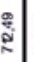 & हై & & 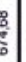 & 焉 & 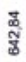 & శ్ \\
\hline ذّ & & & 号 & $\begin{array}{c}\bar{\sigma} \\
\vdots \\
\alpha\end{array}$ & 总 & 离 & $\begin{array}{l}\text { : } \\
\vdots \\
\vdots\end{array}$ & & 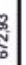 & & $\begin{array}{l}\mathbb{2} \\
\mathbb{్} \\
\mathbb{8}\end{array}$ & 禺 \\
\hline 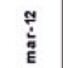 & & & 怘 & $\mid \begin{array}{l}\mathscr{8} \\
\vdots \\
\vdots 2\end{array}$ & ํㅗㄹ & 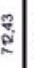 & $\begin{array}{l}E \\
8 \\
8\end{array}$ & & 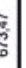 & & 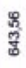 & 离 \\
\hline & 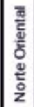 & 8 & 造 & & & & & & & & & \\
\hline 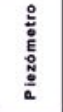 & 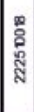 & & : & 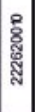 & 怘 & 叧 & 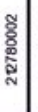 & ఫ్ & 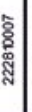 & 8 & & \\
\hline
\end{tabular}

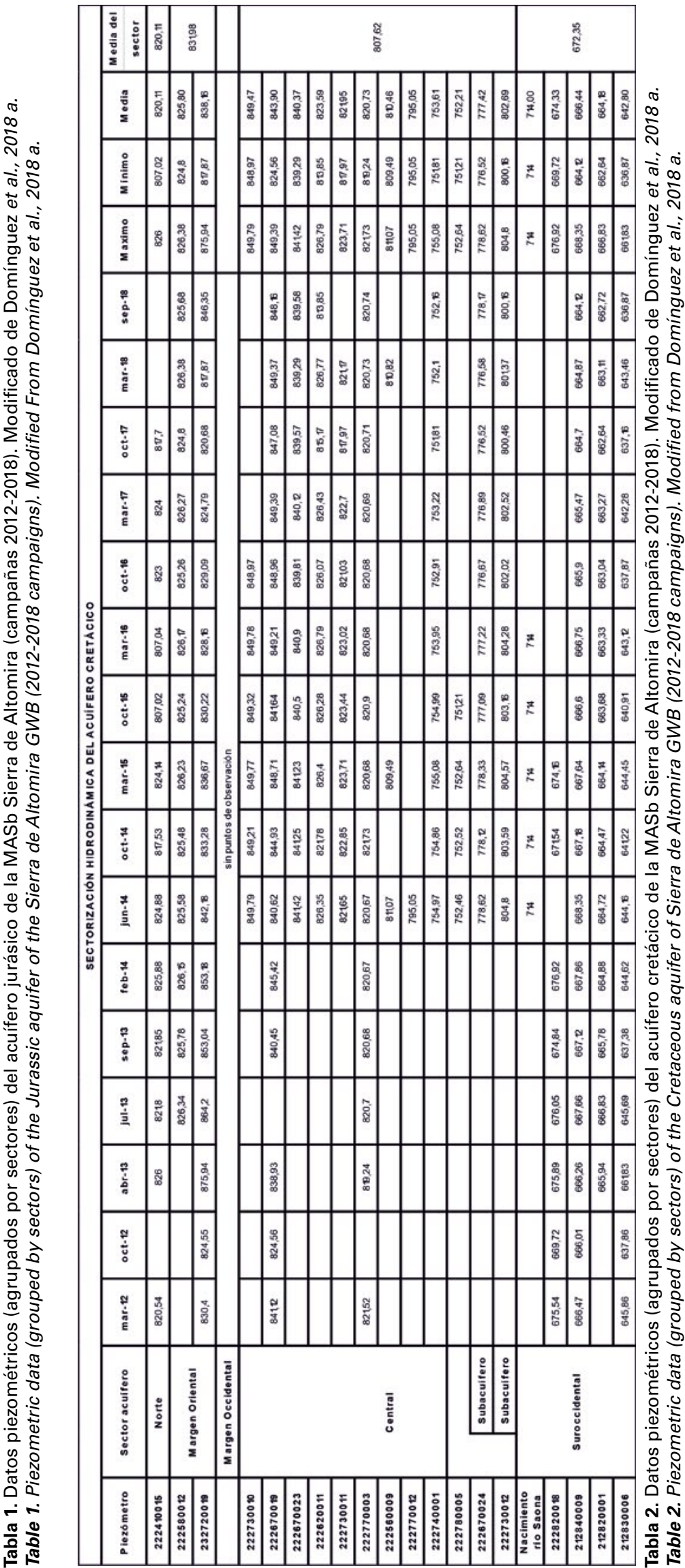




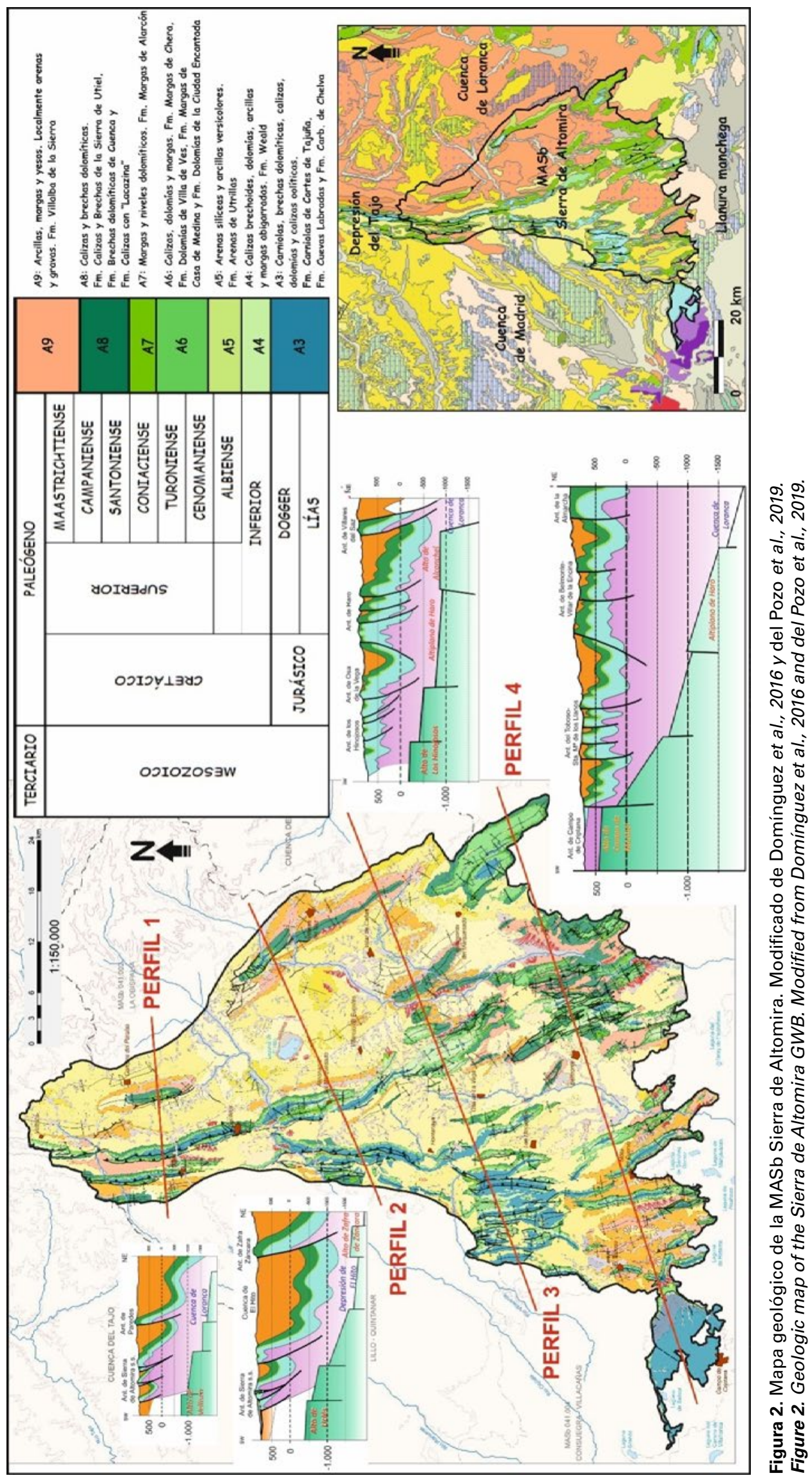


La serie estratigráfica abarca desde el Paleozoico a la actualidad. Los materiales del basamento paleozoico, situados entre $1500 \mathrm{~m}$ y $3000 \mathrm{~m}$ de profundidad, están formados por pizarras, cuarcitas y granitoides.

La serie mesozoica se inicia con un tegumento triásico formado por las areniscas del Buntsandstein y las calizas y dolomías del Muschelkalk. A continuación, se superponen las arcillas yesíferas del Keuper que constituyen el principal nivel de despegue del sistema de cabalgamientos generados durante la Orogenia alpina (figura 3).

Siguen en la serie, mediante contacto discordante, los materiales jurásicos compuestos por un potente paquete de dolomías, brechas carbonatadas, calizas y algunos niveles margosos, de más de $800 \mathrm{~m}$ de espesor, que abarca desde el Lías inferior hasta el Toar-

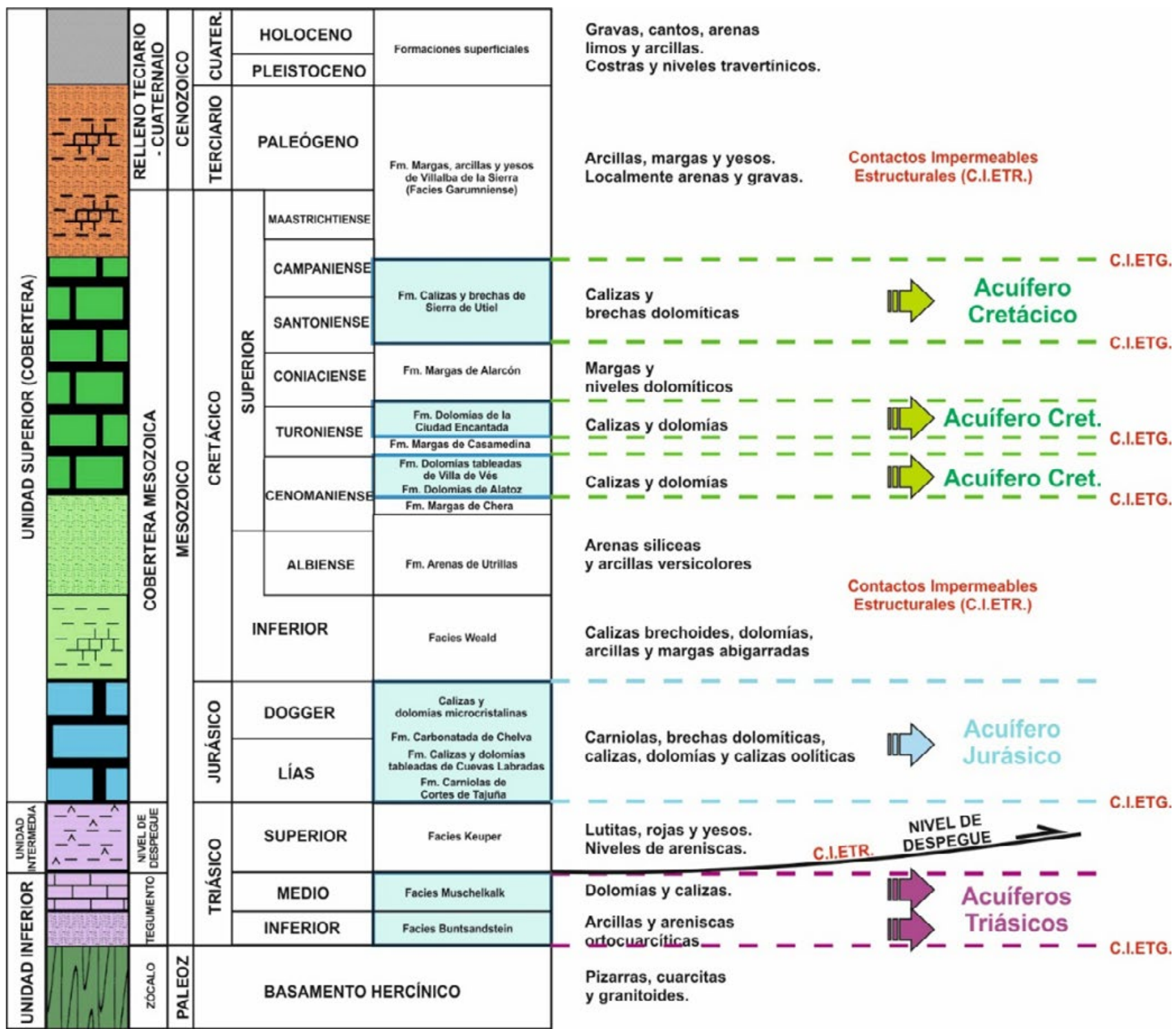

\section{C.I.ETG.: Contacto Impermeable Estratigráfico C.I.ETR.: Contacto Impermeable Estructural}

Figura 3. Unidades estratigráficas de la MASb Sierra de Altomira. Identificación de los niveles acuíferos jurásicos y cretácicos más importantes. Modificado de del Pozo et al., 2019.

Figure 3. Stratigraphic units in the Sierra de Altomira GWB. Identification of the most important Jurassic and Cretaceous aquifers Modified from del Pozo et al., 2019. 
ciense. Por su parte, el Cretácico se divide en tres grupos litológicos: 1) el tramo basal (Cretácico inferior) con predominio de materiales detríticos y arcillosos; 2) el tramo intermedio (Cretácico superior) formado por materiales carbonatados de origen marino y 3) el tramo superior (tránsito cretácico-terciario), constituido por depósitos detríticos, margas, yesos y carbonatos (Díaz et al., 2011).

Los depósitos terciarios, formados por materiales detríticos (arcillas, margas, arenas y conglomerados) y evaporíticos, con intercalaciones de calizas, alcanzan gran desarrollo en las cuencas sedimentarias situadas entre los afloramientos mesozoicos.

Finalmente, el Cuaternario está representado por depósitos aluviales, constituidos por materiales detríticos de escaso espesor (gravas, arenas y conglomerados intercalados en limos y arcillas) (figura 3 ).

\section{Marco hidrogeológico de detalle}

La hidrodinámica de la MASb Sierra de Altomira es muy compleja debido a la presencia de diversos niveles permeables con características y comportamientos diferentes y a una disposición estructural muy condicionada por cabalgamientos, fallas y pliegues. Estas estructuras se orientan preferentemente en dirección norte-sur, con una disposición en forma de abanico invertido, mucho más apretada en la mitad septentrional de la MASb, donde prevalecen los cabalgamientos de gran salto que, en la meridional, donde predominan las estructuras de plegamiento suaves en disposición más abierta.

Por tanto, coexisten una serie de elementos clave que producen una compartimentación hidrogeológica de la MASb en la horizontal o individualizan acuíferos en la vertical.

Por un lado, determinadas estructuras tectónicas pueden provocar compartimentación y desconexiones hidráulicas en la horizontal si actúan como Contactos Impermeables Estructurales (en adelante C.I.ETR.). En la MASb Sierra de Altomira este tipo de límite se suele producir cuando fallas o cabalgamientos ponen en contacto formaciones permeables jurásicas y cretácicas con los materiales arcillosos de la facies Keuper (Triásico).

Existen también límites tectónicos que actúan como umbrales piezométricos o barreras al flujo subterráneo de forma parcial o estacional en función de la cota piezométrica. Se trata de pliegues o pliegues-faIla, de materiales jurásicos y cretácicos, asimétricos, con flancos subverticales o invertidos, y en cuyo núcleo se encuentran materiales impermeables, con frecuencia las arcillas plásticas triásicas. Cuando el nivel piezométrico se encuentra por debajo del con- tacto Jurásico-Keuper, estas estructuras son barreras impermeables y no existe conexión hidráulica entre ambos lados de la misma.

Por otro lado, la presencia de Contactos Impermeables Estratigráficos (en adelante C.I.ETG.), que son los límites entre una formación permeable y otra de baja permeabilidad, impide el flujo subterráneo en la vertical. En la masa de agua subterránea de Sierra de Altomira estos contactos delimitan, dentro de la serie estratigráfica tipo y de base a techo, los siguientes tramos permeables (figura 3):

- Acuíferos carbonatados jurásicos: son los que presentan la mayor superficie de afloramiento. Se inician con los materiales del Lías, compuestos por una alternancia de dolomías en la base, seguidos por calizas y dolomías y calizas a techo. Sobre los mismos encontramos las dolomías del Dogger.Todos estos materiales constituyen el acuífero principal de la MASb con una morfología replegada por la sucesión de sinclinales y anticlinales.

- Acuíferos detríticos cretácicos: en la base se sitúan los depósitos calco-margosos, brechoides y detríticos de la Facies Weald, a los que siguen la Formación Arenas de Utrillas. Por su permeabilidad media-baja se comportan como un nivel semipermeable constituyendo acuíferos de interés local.

- Acuíferos carbonatados cretácicos: en conjunto constituyen el principal acuífero cretácico. Está formado por una alternancia de dolomías, margas y calizas (Cenomaniense-Turoniense), y calizas y brechas (Santoniense-Campaniense) que puede superar los 100 metros de potencia.

- Acuífero calco-yesífero del tránsito cretácico-terciario: alternancia de niveles carbonatados intercalados con arcillas y margas con yesos. Por la mala calidad de sus aguas para el consumo humano es un acuífero poco importante, de escaso aprovechamiento.

- Acuíferos detríticos y carbonatados terciarios: forman un acuífero multicapa poco conocido. Presenta valores bajos de transmisividad. Se distribuye en horizontes arenosos y conglomeráticos alternantes con arcillas con cambios laterales de facies hacia litologías más evaporíticas. A techo de esta serie se depositan las calizas tableadas de origen lacustre del Turoliense, que pueden constituir niveles locales de cierto interés. Suelen formar pequeños acuíferos colgados drenados por manantiales.

- Acuíferos detríticos cuaternarios: están formados por materiales detríticos de origen fluvial. Presentan altos valores de permeabilidad. Tienen interés muy local al circunscribirse a los principales cauces fluviales de la zona. 


\section{Sectorizaciones básicas}

\section{Sectorización hidrodinámica}

Esta sectorización se establece tras el análisis de los resultados de los estudios piezométricos (Galindo et al., 2012, Domínguez et al., 2016 y 2018 a) llevados a cabo dentro del convenio de colaboración IGME-Comunidad de Usuarios de Aguas Subterráneas de la Sierra de Altomira suscrito en el año 2012. Pese a que algunas zo- nas de la MASb cuentan con muy pocos piezómetros, las numerosas campañas de registro realizadas entre 2012 y 2018 (tablas 1 y 2) han permitido comprobar la evolución piezométrica global de la MASb tanto a escala anual (aguas altas y bajas en un mismo año hidrológico) como plurianual (años secos, medios y húmedos). El análisis individualizado de los registros de cada piezómetro y la comparativa entre todos ellos ha permitido establecer una sectorización hidrodinámica de cada acuífero al agruparlos por zonas de similar piezometría y evolución. Los límites entre estas zonas se

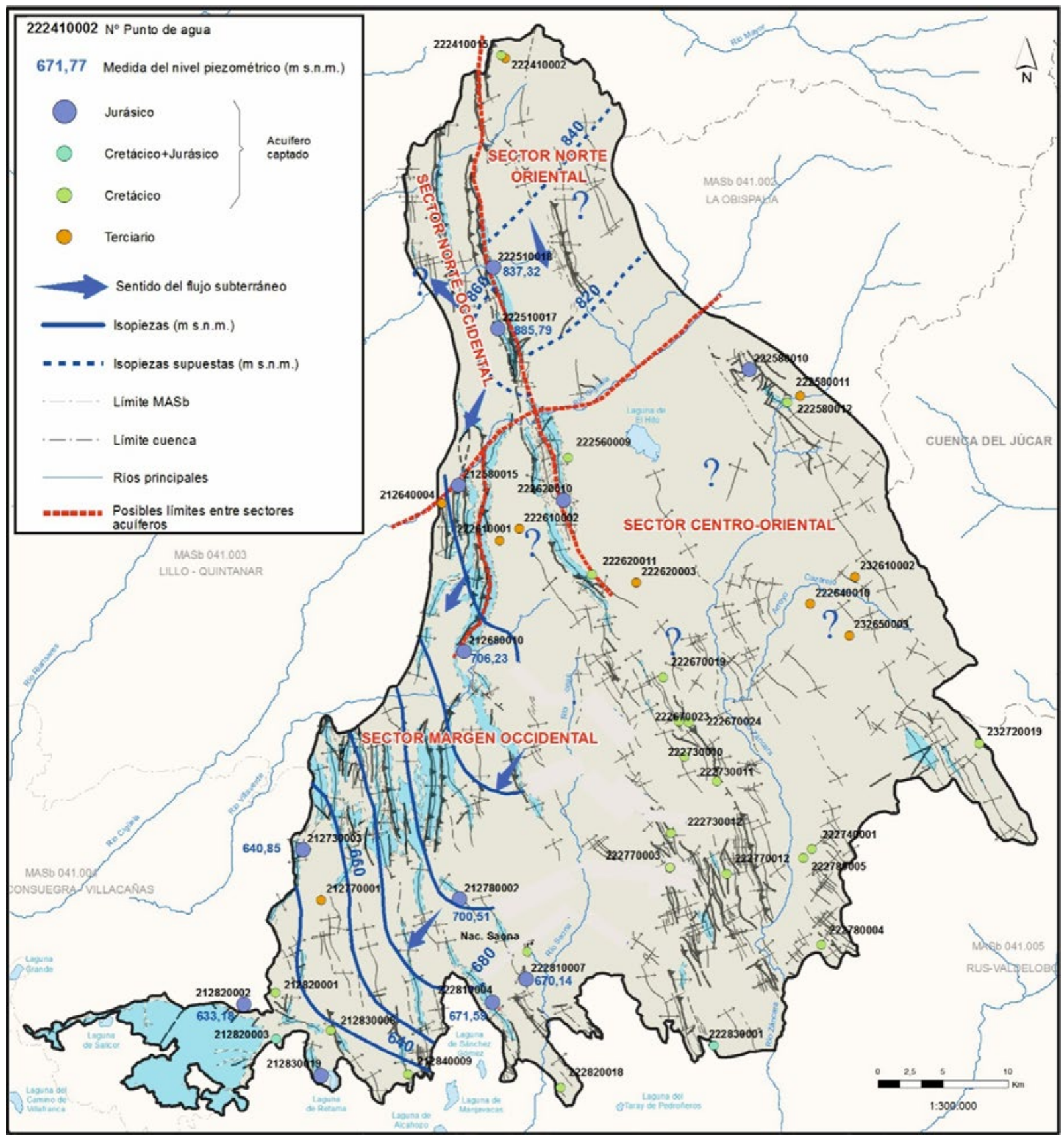

Figura 4. Sectorización del acuífero jurásico a partir de la piezometría (datos de octubre de 2018). Modificado de Domínguez et al., 2018 a. Figure 4. Sectorization based on the piezometry of the Jurassic aquifer (data from October 2018). Modified from Domínguez et al., 2018 a. 
han trazado coincidentes con las principales estructuras que pueden actuar como barreras o semibarreras del flujo subterráneo o con cursos fluviales en los que la relación río-acuífero es especialmente importante.

Para el conjunto permeable jurásico se han diferenciado dos sectores acuíferos al norte del río Gigüela: el sector Norte Oriental y el sector Norte Occidental. Las cotas piezométricas medias (tabla 1) marcan una diferencia del orden de $50 \mathrm{~m}$ a un lado y otro del cabalgamiento que separa ambos puntos de observación y que se extiende, en sentido norte-sur, desde Vellisca a Saelices.
Al sur del río Gigüela se han definido el sector Centro Oriental y el sector Margen Occidental. Como en el caso anterior la diferente cota piezométrica permite asumir que se trata de sectores acuíferos diferentes. El límite entre estos también se ha hecho coincidir con estructuras cabalgantes, tiene orientación norte-sur, y se sitúa en la vertical de la localidad de Almonacid del Marquesado. El sector Centro-Oriental comprende de forma aproximada la práctica totalidad de la cuenca del río Záncara, mientras que el Sector Margen Occidental ocupa todo el vértice suroeste de la MASb.

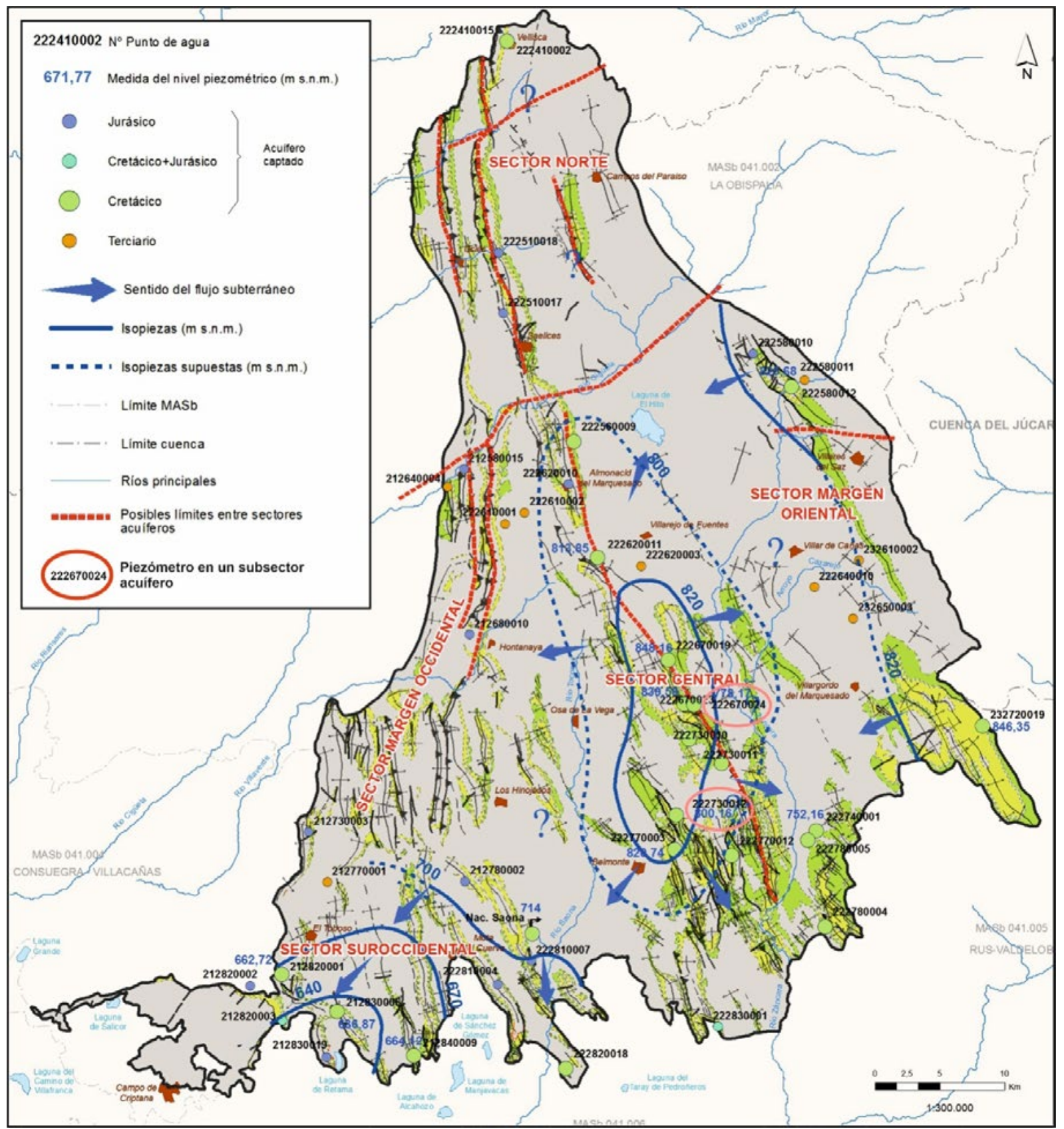

Figura 5. Sectorización del acuífero Cretácico a partir de la piezometría. (datos de octubre de 2018). En Domínguez et al., 2018 a. Figure 5. Sectorization based on the piezometry of the Cretaceous aquifer (data from October 2018). From Domínguez et al., 2018 a. 
La mayor densidad de puntos de observación en este sector permite trazar líneas isopiezas y definir con claridad la dirección del flujo subterráneo de NNE a SSO.

La divisoria entre los sectores septentrionales y meridionales la constituye el río Gigüela, que mantendría relaciones río-acuífero con todos ellos (figura 4).

Por su parte, los niveles carbonatados del Cretácico se han considerado en su conjunto como un único tramo permeable. Al norte del río Gigüela se ha establecido un único sector Norte. En el mismo, diversas estructuras cabalgantes muy probablemente individualizan acuíferos menores, pero el único piezómetro en la zona ha impedido corroborar con datos piezométricos esta posibilidad. Según los registros de este punto de observación, y asumiendo su representatividad para el conjunto del sector, la piezometría media se sitúa en torno a los 820 m s.n.m.

Al sur de dicho cauce se diferencian cuatro sectores acuíferos: en la franja este de la MASb el sector acuífero Margen Oriental, con una cota piezométrica media de 832 m s.n.m.; en el área comprendida entre los ríos Toconar-Saona, al oeste, y Záncara, al este, el sector acuífero Central, con piezometrías sensiblemente menores (807 m s.n.m), y que constituye una especie de domo hidráulico en el que el flujo subterráneo se distribuye de forma radial. Algunos datos piezométricos en esta zona demuestran la presencia de subsectores acuíferos, de pequeña extensión, totalmente independientes, cuyos límites exactos precisan estudios de mayor detalle (tabla 2); el sector acuífero Margen Occidental, situado en el lado oeste de la MASb, que no cuenta con puntos de observación, pero que se ha diferenciado por considerar que las estructuras tectónicas presentes limitan, al menos, un acuífero independiente $y$, finalmente, el sector acuífero Suroccidental, en el extremo suroeste de la MASb Sierra de Altomira, en la zona de contacto con la MASb 041.004 Consuegra-Villacañas y la MASb 041.006 Mancha Occidental II. Los puntos de control de la piezometría en este sector fijan cotas que oscilan entre los $714 \mathrm{~m}$ s.n.m. en el nacimiento del río Saona hasta los $637 \mathrm{~m}$ s.n.m. del piezómetro 212830006 (figura 5). La presencia de afloramientos jurásicos intercalados entre los cretácicos y determinadas estructuras tectónicas que pueden actuar como barreras, impiden hablar de un flujo continuo exclusivo de este nivel acuífero cretácico. No obstante, haciendo esta abstracción, se puede establecer un sentido de flujo para todo el sector dirigido hacia el SSO.

Estos estudios piezométricos (Domínguez et al., 2016 y 2018a) concluyen que el río Gigüela actúa como vía de drenaje de los recursos hídricos en la mitad septentrional de la MASb y puede establecerse como límite entre los sectores acuíferos diferenciados al norte y al sur del mismo. En la mitad sur, el flujo subterráneo, pese a la presencia de algunas estructuras con orientación N-S que actúan como semibarreras hidrogeológicas e individualizan pequeños acuíferos de uso local, tiene, en general, un sentido hacia el sur-suroeste.

Datos piezométricos muy diferentes de zonas próximas confirman la existencia de subsectores acuíferos de pequeño tamaño y totalmente independientes que no han sido diferenciados. Por contra, otros sectores, pese a no contar con datos piezométricos que corroboren hidrodinámicas distintas, se han individualizado atendiendo a la presencia de estructuras que actúan, muy probablemente, como barreras, semibarreras o umbrales piezométricos del flujo subterráneo. Se constata así, que en algunas zonas es necesaria una red piezométrica más densa para establecer con mayor precisión estos límites.

\begin{tabular}{|c|c|c|c|c|c|c|}
\hline \multirow{3}{*}{ Bloque } & \multicolumn{6}{|c|}{ Sectores acuíferos hidrodinámicos } \\
\hline & \multirow{2}{*}{ Sector } & \multirow{2}{*}{$\begin{array}{l}\text { Extensión aprox. } \\
\qquad(\mathrm{Km} 2)\end{array}$} & \multicolumn{2}{|c|}{$\begin{array}{l}\text { Nivel piezométrico medio } \\
\text { (m s.n.m.) }\end{array}$} & \multirow{2}{*}{ Morfología } & \multirow{2}{*}{ Características hidrogeológicas } \\
\hline & & & Ac. Cretácico & Ac. Jurásico & & \\
\hline \multirow{6}{*}{ Norte } & 1 & 44 & 820,11 & Sin dato & \multirow{6}{*}{$\begin{array}{l}\text { Sectores aculferos pequenios, estrechos y } \\
\text { alargados en sentido norte-sur. }\end{array}$} & \multirow{6}{*}{$\begin{array}{l}\text { Los limites entre bloques se han trazado a aprtir de fallas } \\
\text { y pliegues orientadas norte-sur, que actúan como barreras } \\
\text { hidrogeológicas y de las fallas transversales que las cortan } \\
\text { Los esacos dáos piezomátricos justifican varios de estos } \\
\text { limites }\end{array}$} \\
\hline & 2 & 16 & Sindato & Snctato & & \\
\hline & 3 & 120 & Sndato & Sndto & & \\
\hline & 4 & 137 & Sndato & 837,97 & & \\
\hline & 5 & 82 & Sindato & 887,11 & & \\
\hline & 6 & 43 & Sindato & Sndato & & \\
\hline \multirow{5}{*}{ Sur } & 7 & 90 & 825,8 & 836,26 & \multirow{5}{*}{$\begin{array}{c}\text { Dos gandes sectores acuiferos que dividen } \\
\text { en dos mitades (oriental y occidenta) este } \\
\text { bloque. } \\
\text { Tres sectores menores, estrechos y } \\
\text { adagados en sentido nortesur, en los } \\
\text { extremos nororiental y noroccidenta del } \\
\text { bloque. }\end{array}$} & \multirow{5}{*}{$\begin{array}{l}\text { Las estructuras tectónicas principales, orientadas en } \\
\text { dirección norte-sur, y las que las cortan transversamente } \\
\text { no actúan, en general, como barreras del flujo } \\
\text { subterráneoicos. } \\
\text { La piezometría sustena esta menor división al permiten } \\
\text { definir un flujo subterráneo "genera" continuo en sentido } \\
\text { sur y suroeste. }\end{array}$} \\
\hline & 8 & 845 & 788,61 & Indto & & \\
\hline & 9 & 1111 & 760,16 & 668,4 & & \\
\hline & 10 & 36 & Sndto & Sndto & & \\
\hline & 11 & 51 & Sndto & 724,66 & & \\
\hline \multicolumn{2}{|c|}{ Limite entre bloques } & \multicolumn{5}{|c|}{$\begin{array}{l}\text { Coincide aproximadamentecon el trazado del rio Gigüela } \\
\text { La piezometria a ambos lados del limitees distinta, por lo que justificala presencia de un limite hidrogeológio daro. }\end{array}$} \\
\hline
\end{tabular}

Tabla 3. Características de los sectores hidrodinámicos.

Table 3. Characteristics of the hydrodynamic sectors. 
Las principales divisorias establecidas con estos criterios coinciden tanto en el tramo permeable Jurásico como en el Cretácico. Debido a ello, se puede definir una sectorización hidrodinámica combinada en la que se representan 11 sectores acuíferos. Cada uno de estos sectores incluiría en la vertical ambos niveles permeables analizados. En la tabla 3 se indican las características generales de estos sectores y datos relativos a la piezome- tría media. No obstante, en algunos sectores no se cuenta con piezómetros de observación (figura 6 y tabla 3 ).

En el denominado bloque septentrional (al norte del río Gigüela) se identifican seis sectores acuíferos (1 a 6) de morfología estrecha y alargada.

El bloque sur incluye dos grandes sectores, uno en el lado oriental (sector 8) y otro en el occidental (sector 9). El límite entre ambos se ha trazado paralelo a estructuras

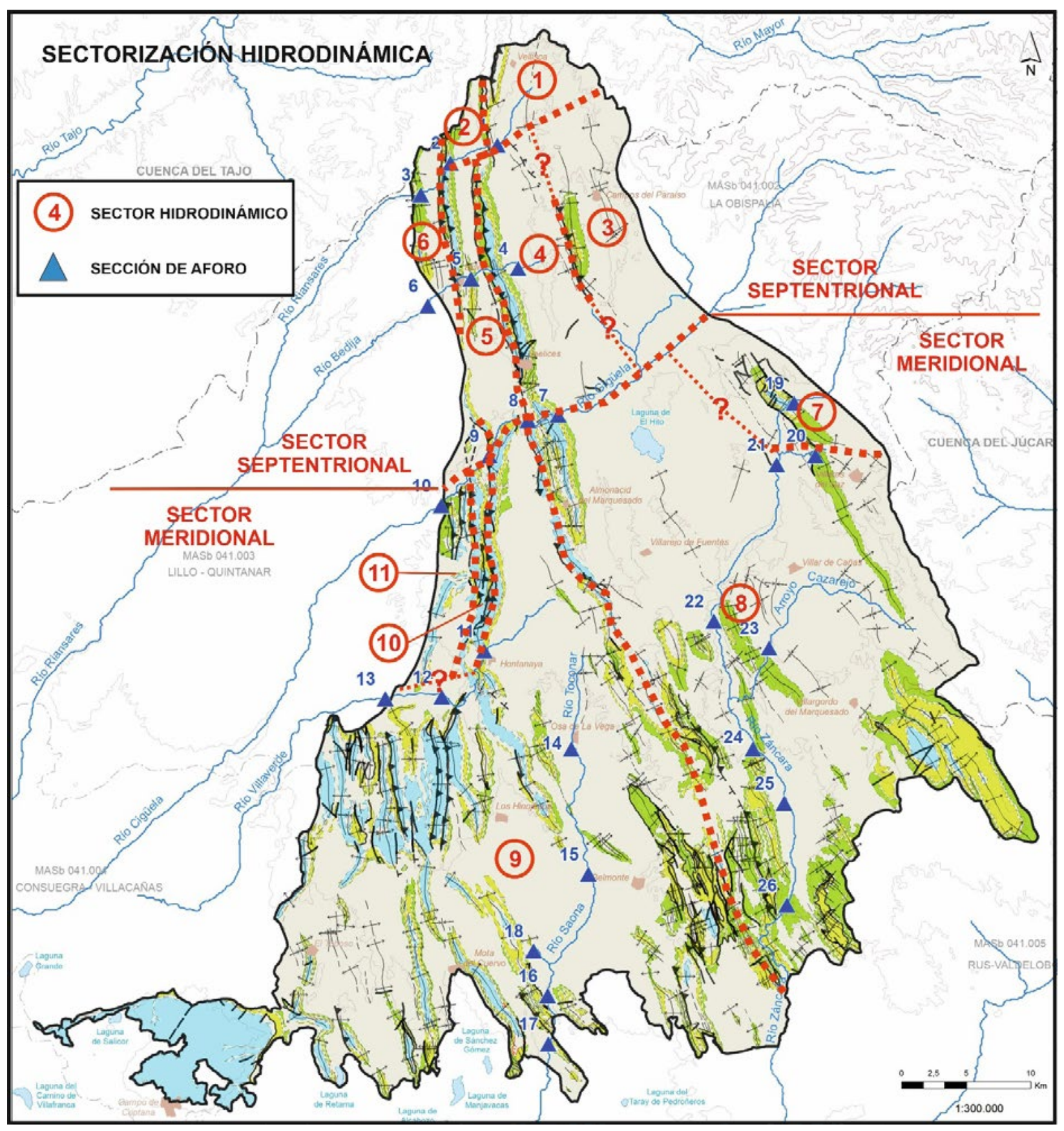

Figura 6. Sectorización hidrodinámica resultante de la combinación de los sectores establecidos a partir de la piezometría de los acuíferos jurásico y cretácico. Modificado de Domínguez et al., 2018 a.

Figure 6. Hydrodinamic sectorization resulting from the combination of the sectors established from the piezometry of the Jurassic and Cretaceous aquifers. Modified from Domínguez et al., 2018 a. 
tectónicas que constituyen barreras del flujo subterráneo en la mitad septentrional (cabalgamientos y fallas) y un umbral piezométrico en la meridional (anticlinorios). Este límite coincidiría en superficie, de forma aproximada, con la divisoria de las cuencas de los ríos Toconar-Saona y Záncara. Se han diferenciado además otros tres sectores menores, uno en el extremo nororiental (sector 7) y otros dos en el margen noroccidental (sectores 10 y 11).

\section{Sectorización tectónica}

La sectorización tectónica que se propone se fundamenta en las conclusiones del análisis estructural de la MASb Sierra de Altomira realizado por del Pozo et al. (2019), donde se establece un esquema progresivo de división de la misma, desde una escala regional a una escala local, a partir del condicionamiento que ejerce la estructura del basamento sobre la disposición de las series suprayacentes dadas las características de los distintos materiales y su diferente respuesta a los esfuerzos tectónicos.

A escala regional la compartimentación responde a la morfología del basamento (unidad tecto-estratigráfica inferior) (figura 3), compuesto por una serie de horsts y grabens que configuran grosso modo una zonificación básica en dos bloques, uno septentrional deprimido y otro meridional elevado (figura 7).

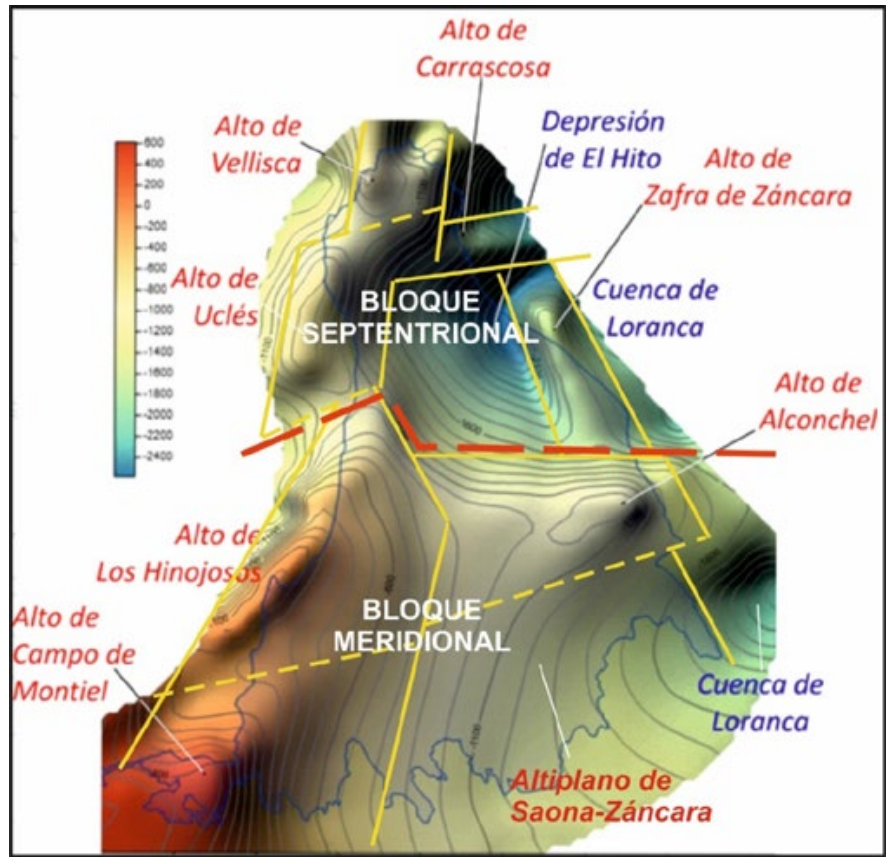

Figura 7. Sectorización regional a partir de la estructura en bloques del basamento identificado mediante isobatas del techo. Modificado de del Pozo et al., 2019.

Figure 7. Regional sectorization from the basement block structure, identified by roof isobaths. Modified from del Pozo et al., 2019.

\begin{tabular}{|c|c|c|c|c|c|}
\hline \multirow[b]{2}{*}{ Bloque } & \multicolumn{5}{|c|}{ Sectores acuiferos tectónicos } \\
\hline & Sector & $\begin{array}{l}\text { Extensión aprox. } \\
\qquad(\mathrm{Km} 2)\end{array}$ & Acuífero aflorante & Morfología & Características hidrogeológicas \\
\hline \multirow{6}{*}{ Norte } & 1 & 13 & Jurásico+Cretácico & \multirow{6}{*}{$\begin{array}{l}\text { Sectores acuiferos pequeños, estrechos y } \\
\text { alargados en sentido norte-sur. }\end{array}$} & \multirow{6}{*}{$\begin{array}{l}\text { Los limites entre bloques se han trazado a partir de fallas, } \\
\text { cabalgamientos y pliegues orientadas norte-sur, que } \\
\text { actúan como barreras hidrogeológicas. } \\
\text { Los limites norte y sur de los sectores se corresponden } \\
\text { con zonas de trasnferencia tectónica (hidrogeológica). } \\
\text { En el margen nororiental (sectores } 2,3 \text { y } 7 \text { ) escasos } \\
\text { afloramientos cretácicos. En el resto de sectores }(1,4,5 \text { y } \\
\text { 6) se intercalan afloramientos jurásicos y cretácicos a } \\
\text { partir de trenes de cabalgamientos. }\end{array}$} \\
\hline & 2 & 16 & Cretácico & & \\
\hline & 3 & 44 & Cretáciō & & \\
\hline & 4 & 30 & Urásico+Cretácio & & \\
\hline & 5 & 82 & Jurásico+Cretácio & & \\
\hline & 6 & 137 & Jurásico+Cretáciō & & \\
\hline \multirow{7}{*}{ Sur } & 8 & 80 & Jurásico+Cretácico & \multirow{7}{*}{$\begin{array}{c}\text { Sectores acuíferos más extensos conforme } \\
\text { nos trasladamos hacia el sur de la MASb. } \\
\text { La morfología de los sectores menores }(8,9 \\
11 \text { y 13) es estrecha y alargada en sentido } \\
\text { norte-sur, mientras que en los sectores más } \\
\text { amplios (10,12 y 14) es alargada en sentido } \\
\text { oeste-este. }\end{array}$} & \multirow{7}{*}{$\begin{array}{c}\text { Las estructuras tectónicas principales, orientadas en } \\
\text { dirección norte-sur, así como los límites trazados con } \\
\text { dirección este-oeste a partir de las zonas de transferencia } \\
\text { hidrogeológica no actúan, en general, como barreras del } \\
\text { flujo subterráneo. } \\
\text { En todos los sectores hay afloramientos pertenecientes a } \\
\text { los acuiferos Jurásico y Cretácico, salvo en el sector } 13 \text { en } \\
\text { el que solo afloran materiales permeables del acuifero } \\
\text { Cretácico. } \\
\text { (*) En el extremo sureoeste del sector 14, en el área de } \\
\text { Campo de Criptana, solo existe el acuifero Jurásico. }\end{array}$} \\
\hline & 9 & 87 & Jurásico+Cretáciō & & \\
\hline & 10 & 290 & Jurásico+Cretácico & & \\
\hline & 11 & 44 & Irrásico+Cretáciō & & \\
\hline & 12 & 737 & Juŕsico+Cretácio & & \\
\hline & 13 & 70 & Cretáciø & & \\
\hline & 14 & 825 & Jurásico+Cretácico(*) & & \\
\hline \multicolumn{2}{|c|}{ Límite entre bloques } & \multicolumn{4}{|c|}{ Coincide aproximadamente con el trazado del río Gigiela y la zona de transferencia tectónica (hidrogeológica) del mismo nombre. } \\
\hline
\end{tabular}

Tabla 4. Características de los sectores tectónicos.

Table 4. Characteristics of the tectonic sectors. 


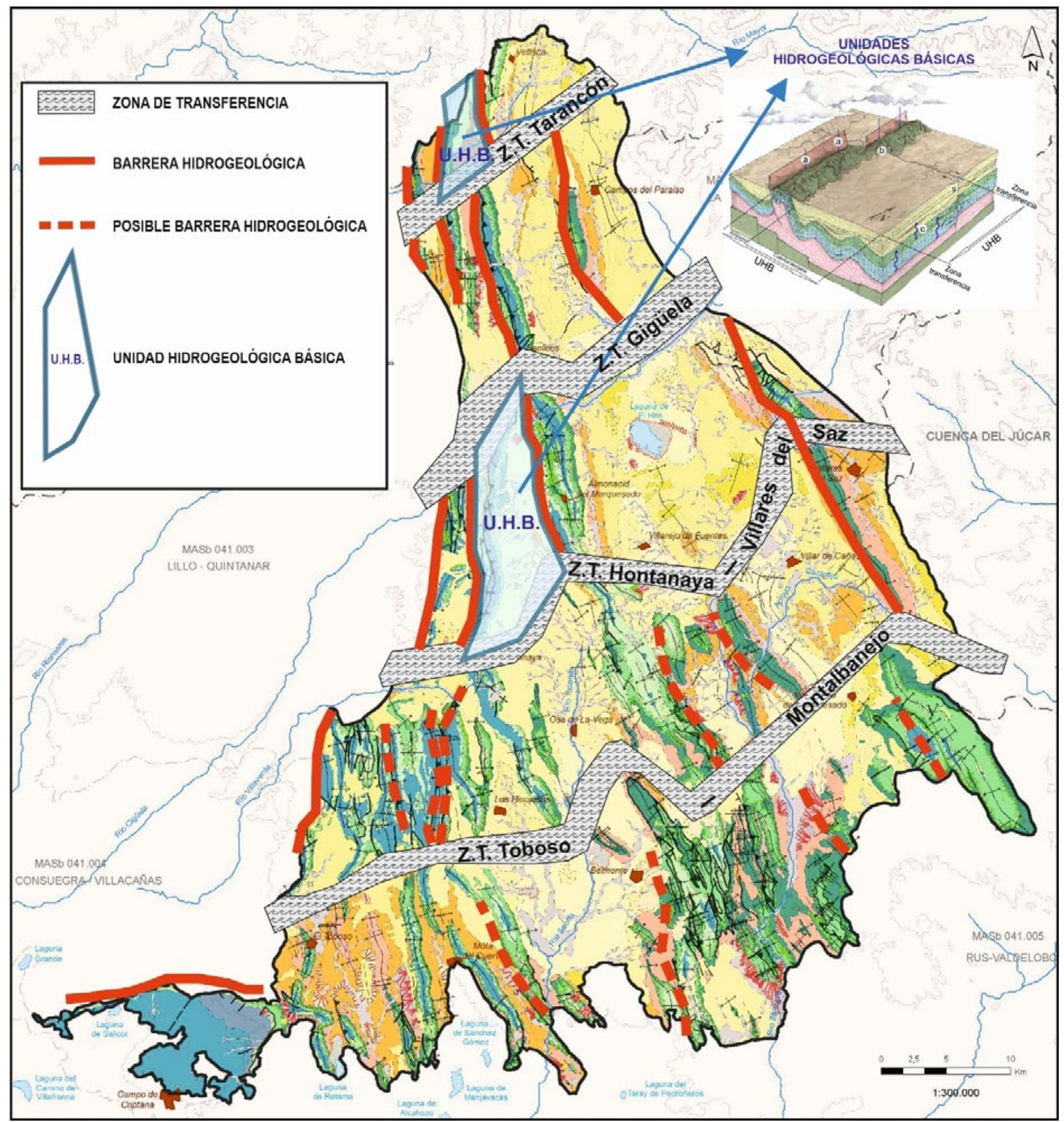

Figura 8. Sectorización local a partir de lineaciones estructurales aflorantes que actúan como barreras cerradas al flujo subterráneo (divisorias seguras - trazo continuo), o que pueden actuar como tales (divisorias posibles - trazo discontinuo), modificado de del Pozo et al., 2019.

Figure 8. Local sectorization from outgoing structural lineaments that act as closed barriers to the underground flow (safe dividers continuous line), or that can act as such (possible divisions - discontinuous line), modified from del Pozo et al., 2019.

La compartimentación intermedia se fundamenta en la disposición espacial del Mesozoico (unidad superior o cobertera), que origina los relieves jurásicos y cretácicos que delimitan las cuencas terciarias. Estos materiales están afectados por pliegues, fallas y cabalgamientos cuyo nivel de despegue se sitúa en los materiales plásticos de la facies Keuper (unidad intermedia) (figura 3). Finalmente, se delimitan las Unidades Hidrogeológicas Básicas (UHB) que, como áreas estructurales menores, hidrogeológicamente independientes, permiten configurar una sectorización a escala local (figura 8) (del Pozo et al., 2019).

Los límites este y oeste de estas UHB están trazados a partir de las fallas, cabalgamientos y pliegues, referidos en la compartimentación intermedia, que actúan como barreras, seguras o supuestas, del flujo subterráneo. Estas estructuras de cierre son cortadas por otras fracturas transversales, que generan áreas 
de debilidad (zonas de transferencia tectónica) y constituyen los límites septentrional y meridional de las UHB. Se trata de límites en los que no se interrumpe la circulación del agua subterránea, permitiendo transferencias entre UHB contiguas, por lo que actúan como zonas de transferencia hidrogeológica.

A partir de las UHB con márgenes laterales seguros (barreras hidrodinámicas), se ha dividido la MASb Sierra de Altomira en 14 sectores acuíferos (figura 9 y ta- bla 4). Al norte del río Gigüela; donde los cabalgamientos están más apretados y presentan mayores saltos, se individualizan 7 pequeños sectores, con una morfología estrecha y alargada en sentido norte-sur. Por contra, al sur de dicho cauce las estructuras tectónicas son más laxas y las desconexiones hidráulicas menos efectivas. En esta zona meridional, mucho más extensa, se establecen otros siete sectores, en general más amplios y alargadas en sentido oeste-este.

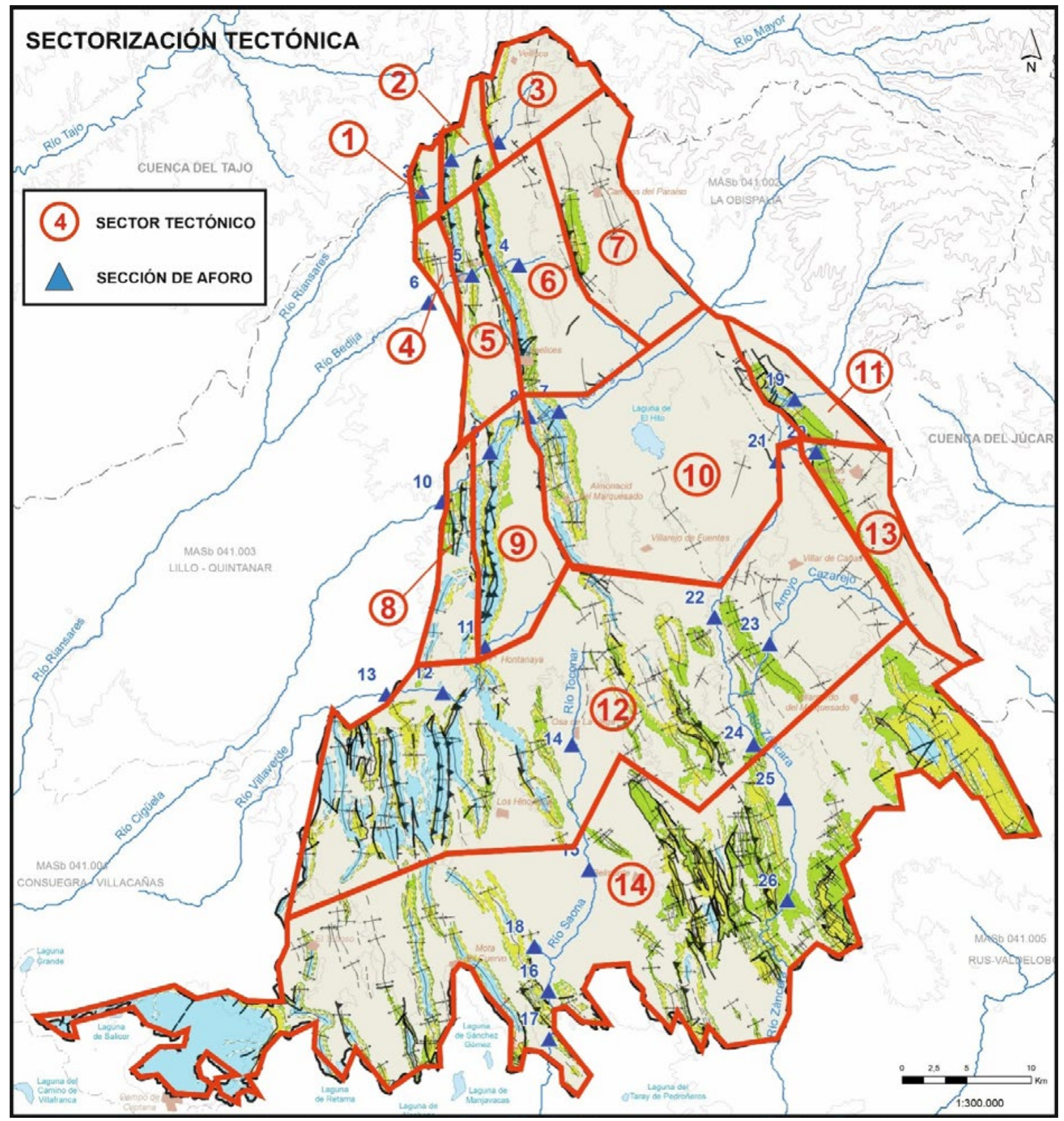

Figura 9. Sectorización tectónica resultante de identificar las UHB en la MASb Sierra de Altomira cuyos márgenes este y oeste actúan como barreras seguras del flujo de agua subterráneo. Modificado de del Pozo et al., 2019.

Figure 9. Tectonic sectorization resulting from identifying the UHB in the Sierra de Altomira GWB where the east and west margins act as safe barriers to the underground water flow Modified from del Pozo et al., 2019. 
En todos los sectores coexisten en la vertical los dos acuíferos principales, no obstante, solo afloran materiales del Cretácico en los sectores 2, 3, 7 y 13. Hay que indicar, además, que en el extremo suroccidental del sector 14, en el área de Campo de Criptana, solo afloran materiales jurásicos, por lo que en esta zona el único acuífero presente es el correspondiente a los materiales de esta edad.

\section{Comparativa con otras sectorizaciones}

Las sectorizaciones, hidrodinámica y tectónica, anteriores se comparan con una sectorización de la MASb basada en la distribución espacial de la red hidrográfica y con el carácter ganador o perdedor de los principales cursos de agua.

\section{Correlación con la red hidrográfica}

El trazado de los cursos fluviales viene determinado por la facilidad de estos para encajarse en la superficie topográfica, ya sea aprovechando la presencia de materiales blandos o las zonas de debilidad que crean las fallas o fracturas perpendiculares a las principales estructuras de plegamiento (zonas de transferencia tectónica).

Los ríos más importantes de la MASb Sierra de Altomira, ordenados de norte a sur, son: Riansares y Bedija, con orientación noreste-suroeste; Gigüela, que cruza la MASb de este-noreste a oeste-suroeste; Villaverde, orientado de noreste a suroeste y Toconar-Saona y Záncara que discurren de norte a sur.

Según estas orientaciones, se puede realizar una división simplista de la MASb en dos mitades, septentrional y meridional (tabla 5), en donde los cursos de la mitad norte de la MASb discurren en sentido SO coincidente con la orientación (NE-SO) de las fallas de Tarancón y Gigüela. Tanto estas fallas como los ríos cortan perpendicularmente a las series de cabalgamientos y pliegues del área y generan zonas de transferencia tectónica- hidrogeológica en donde los cauces establecen con cada afloramiento mesozoico relaciones río-acuífero.

\begin{tabular}{|c|c|c|c|}
\hline Sector & Cauce & Orientación & Características \\
\hline \multirow{4}{*}{ Norte } & Riansares & NE-SO & \multirow{4}{*}{$\begin{array}{l}\text { Cauces de dirección coincidente } \\
\text { con las fallas que cortan las } \\
\text { principales estructuras de } \\
\text { plegamiento (zonas de } \\
\text { transferencia) }\end{array}$} \\
\hline & Bedija & NE-SO & \\
\hline & Gigiela & ENE-OSO & \\
\hline & Villaverde & NE-SO & \\
\hline \multirow{2}{*}{ Sur } & Toconar-Saona & $\mathrm{N}-\mathrm{S}$ & \multirow{2}{*}{$\begin{array}{l}\text { Rios paralelos a las principales } \\
\text { estructuras de plegamiento }\end{array}$} \\
\hline & Záncara & N-S & \\
\hline
\end{tabular}

Tabla 5. Sectorización según la orientación de los ríos de la MASb Sierra de Altomira.

Table 5. Sectorization according to the orientation of the rivers of the MASb Sierra de Altomira.
Por su parte, los ríos de la mitad sur de la MASb tienen orientación N-S y se alinean de forma subparalela a la dirección estructural de los cabalgamientos y pliegues presentes en esta zona. Solo puntualmente atraviesan transversalmente los afloramientos jurásicos y cretácicos (figura 10).

\section{Correlación con las relaciones río-acuífero}

Se entiende como relación río-acuífero a la que se establece entre las aguas superficiales (ríos) y las aguas subterráneas (acuíferos) producto del intercambio hídrico entre las mismas y que se produce en aquellos tramos en los que el río discurre sobre formaciones permeables o se encuentra próximo a ellas, dando lugar a ríos, o tramos de río, ganadores o efluentes y perdedores o influentes (Winter, 1995; Winter et al., 1998).

Según esta relación y con base en los resultados obtenidos en las campañas de aforos en aguas altas (marzo-abril) y bajas (octubre) realizadas entre 2016 y 2018 (Domínguez et al., 2018b), se han clasificado los cauces de la MASb Sierra de Altomira y se han trazado unas divisorias en los puntos en los que se produce un cambio en el tipo de relación (tabla 6 y figura 11).

\begin{tabular}{|c|c|c|c|c|c|c|c|}
\hline \multirow{2}{*}{ Cauce } & \multirow{2}{*}{$\begin{array}{c}\text { Sección de } \\
\text { aforo }\end{array}$} & \multicolumn{6}{|c|}{ Fecha } \\
\hline & & $12-04-16$ & $18-10-16$ & 04-04-17 & $03-10-17$ & 06-03-18 & 02-10-18 \\
\hline \multirow{3}{*}{ Riansares } & 1 & 85,5 & 8,9 & 13,27 & 0 & 32,72 & 5,77 \\
\hline & 2 & 75,3 & 10,22 & 9,87 & 0 & 10,11 & 0 \\
\hline & 3 & 81,62 & 17,75 & 34,7 & 11,59 & 19,24 & 22,29 \\
\hline \multirow{3}{*}{ Bedija } & 4 & 6,53 & 3,5 & 7,62 & 0,3 & 5,99 & 2,29 \\
\hline & 5 & 9,97 & 9,14 & 3,93 & 251 & 2,96 & 4,46 \\
\hline & 6 & 7,95 & 0 & 0 & 0 & 0 & 0 \\
\hline \multirow{4}{*}{ Gigūela } & 7 & 707,2 & 267,6 & 291,6 & 122,3 & 508,2 & 173,4 \\
\hline & 8 & & 157,8 & 282,7 & 99,69 & 371,2 & 185,3 \\
\hline & 9 & 460,4 & 282,68 & 376,17 & 89,49 & 377,63 & 188,9 \\
\hline & 10 & 587,7 & 267,1 & 347,8 & 133,9 & 545,7 & 237,7 \\
\hline \multirow{3}{*}{ Villaverde } & 11 & 7,33 & 2,55 & 4,13 & 0,736 & 4,91 & 1,81 \\
\hline & 12 & 0 & 0 & 0 & 0 & 0 & 0 \\
\hline & 13 & 0 & 0 & 0 & 0 & 0 & 0 \\
\hline \multirow{5}{*}{ Moureal-Saona } & 14 & 9 & 9 & 1,27 & 0,158 & 30,22 & 0 \\
\hline & 15 & 0 & 0 & 0 & 0 & 0,1 & 0 \\
\hline & 16 & 0 & 0 & 16,15 & 0 & 37,42 & 0 \\
\hline & 17 & 0 & 0 & 0 & 0 & 0 & 0 \\
\hline & 18 & 1,59 & 0 & 0 & 0 & 0 & 0 \\
\hline \multirow{8}{*}{ Záncara } & 19 & 190,5 & 4,25 & 69,87 & 0 & 112,04 & 0 \\
\hline & 20 & 22,3 & 0,6 & 2,52 & 0 & 0,2 & 0 \\
\hline & 21 & 193,4 & 25,5 & 80,13 & 6,537 & 60,07 & 33,67 \\
\hline & 22 & 336,1 & 136,7 & 228,2 & 130,9 & 377,2 & 77,15 \\
\hline & 23 & 43,27 & 1.00 & 5,72 & 0,01 & 70,78 & 4,19 \\
\hline & 24 & 471.00 & 143,8 & 166,1 & 71,26 & 506,8 & 131.00 \\
\hline & 25 & 454,7 & 144,53 & 223,52 & 89,46 & 356,82 & 133,61 \\
\hline & 26 & 518,2 & 133,6 & 207.00 & 90,16 & 352,8 & 130,3 \\
\hline
\end{tabular}

Tabla 6. Caudales (I/s) medidos en las secciones de aforo de los ríos de la MASb Sierra de Altomira (periodo 2016-2018). En Domínguez et al., $2018 \mathrm{~b}$

Table 6. Flow (I/s) measured in the river capacity sections of the Sierra de Altomira GWB (period 206-2018). From Domínguez et al., $2018 b$. 

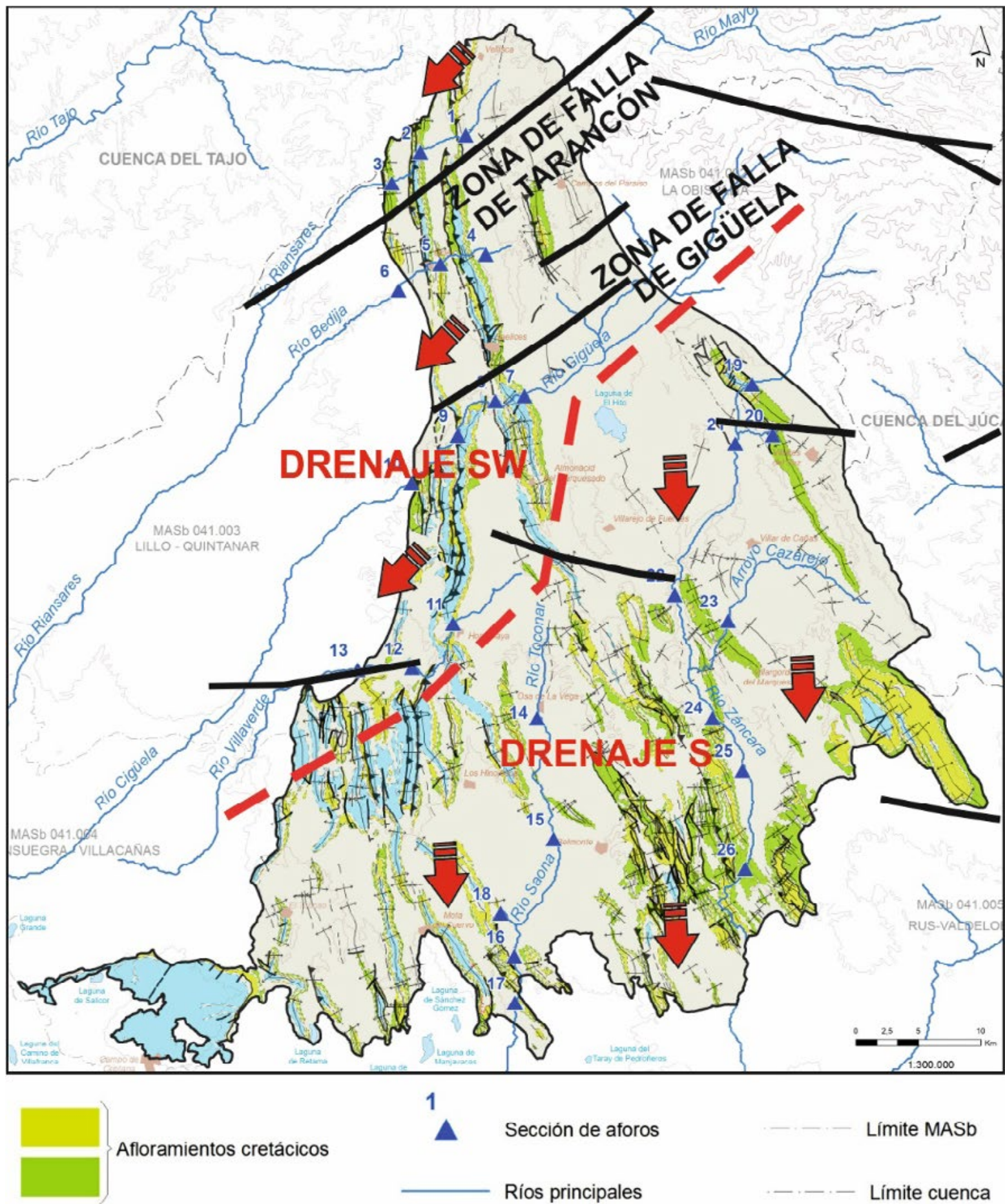

1

Afloramientos cretácicos

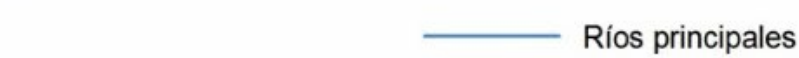

Afloramientos jurásicos
- Sección de aforos

Rios principales

Embalses; Lagunas
Límite MASb

Límite cuenca

Poblaciones

\section{Dirección de drenaje de los cauces}

\section{Zonas de fractura}

Figura 10. Ríos de la MASb Sierra de Altomira. Secciones de aforo. Principales estructuras transversales y direcciones de drenaje de los cauces. Modificado de Domínguez et al., $2018 \mathrm{~b}$.

Figure 10. Rivers in the Sierra de Altomira GWB. Flow measurement sections. Main transverse structures and river drainage direction. Modified from Domínguez et al., 2018 b. 
En el río Riansares se han diferenciado dos tramos con diferente relación río-acuífero, uno perdedor y otro ganador.

El río Bedija es ganador en su parte alta y aguas abajo actúa como cauce influente o perdedor.

En el río Gigüela se han establecido tres tramos con diferente relación río-acuífero. La sección de cabecera es básicamente perdedora, el tramo intermedio tiene carácter ganador, y el tramo más bajo presenta un comportamiento variable.

El río Villaverde, de escaso caudal, se ha comportado a lo largo del periodo de medidas y en todos sus tramos, siempre como perdedor.

El río denominado Toconar en su curso alto y Saona en el resto, salvo de forma ocasional en algún tramo, ha tenido un carácter perdedor.

Finalmente, el del río Záncara, el más caudaloso de la MASb Sierra de Altomira y el más antropizado,

\begin{tabular}{|c|c|c|}
\hline Sector & Cauce & $\begin{array}{c}\text { Tipo de ralación río- } \\
\text { acuífero }\end{array}$ \\
\hline \multirow{3}{*}{ Norte } & Riansares & \multirow{3}{*}{ Variable } \\
\hline & Bedija & \\
\hline & Gigïela & \\
\hline \multirow{2}{*}{ Suroccidental } & Villaverde & \multirow{2}{*}{ Influente } \\
\hline & Toconar-Saona & \\
\hline Suroriental & Záncara & Efluente \\
\hline
\end{tabular}

Tabla 7. Sectorización según el tipo de relación río-acuífero de los cauces de la MASb Sierra de Altomira

Table 7. Sectorization according to the river-aquifer relation of the rivers of the Sierra de Altomira GWB.

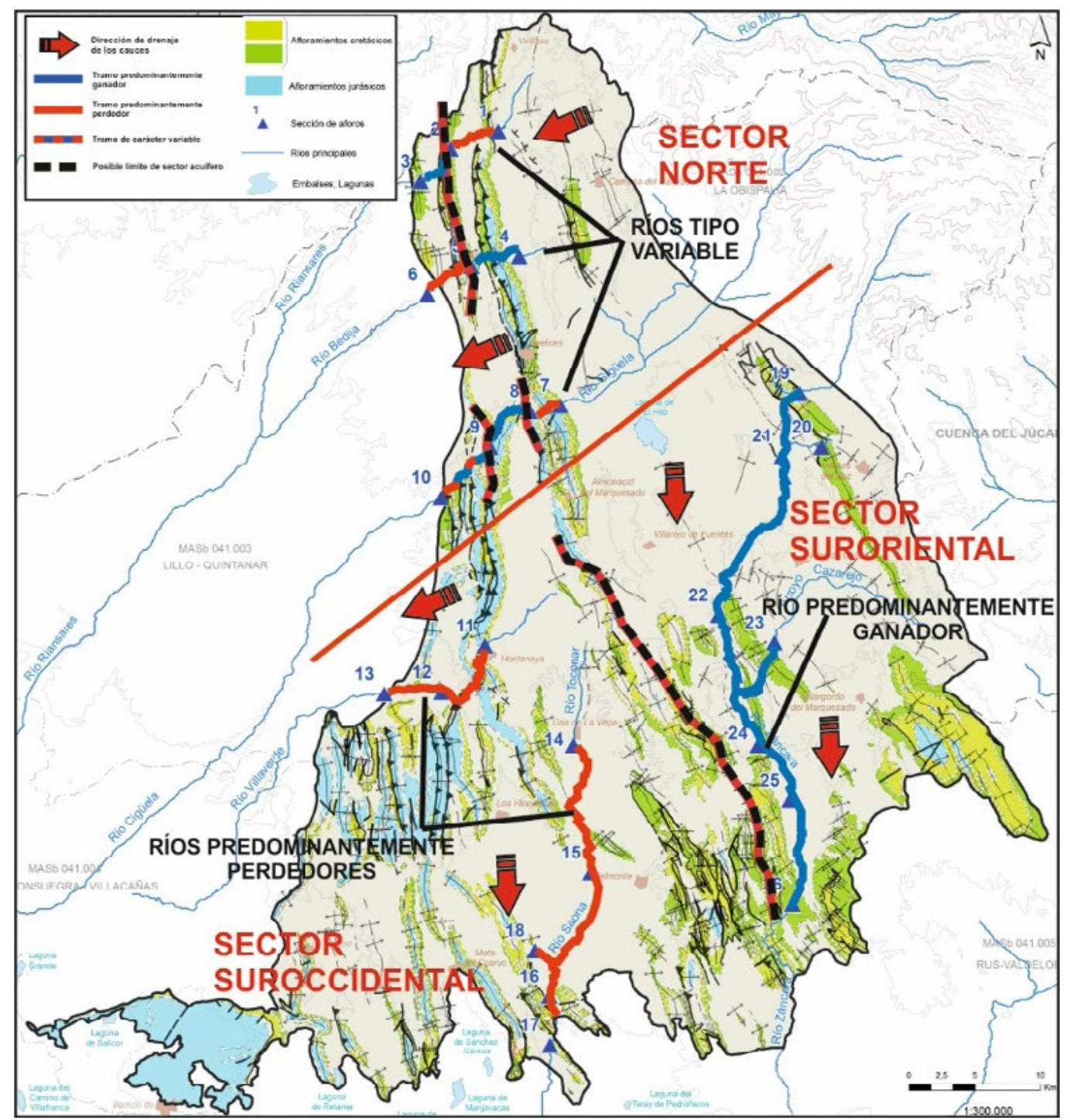

Figura 11. Ríos de la MASb Sierra de Altomira en función de su relación río-acuífero. Modificado de Domínguez et al., 2018 b. Figure 11. Rivers in the Sierra de Altomira GWB based on the river-aquifer relationship. Modified from Domínguez et al., 2018 b. 
tiene un carácter variable en muchos de sus tramos, pero con un claro predominio global como efluente o ganador.

Una sectorización basada en estos criterios permite diferenciar tres tipos de cauces: ganadores, perdedores y de relación variable. Grosso modo, la MASb Sierra de Altomira se dividiría en dos grandes bloques, norte y sur, separados a partir de la divisoria de aguas entre la cuenca hidrográfica del río Gigüela y las de los cauces situados al sur de la misma (figura $11 \mathrm{y}$ tabla 7).

\section{Análisis de resultados}

En el presente artículo se definen dos criterios de sectorización de la MASb Sierra de Altomira, uno en función de datos piezométricos y otra a partir del análisis estructural.

Los resultados se han contrastado entre sí, y también con la distribución de la red hidrográfica y con la relación río-acuífero de los principales cauces de la MASb, comprobando las correlaciones existentes y constatando que existen notables similitudes entre las divisorias proyectadas en la MASb al aplicar unos u otros criterios (figura 12).

Destaca el hecho de que se puede dividir la MASb, básicamente, en dos grandes bloques, septentrional y meridional, separados aproximadamente por la línea que traza el cauce del río Gigüela (tabla 8).

A mayor detalle, la configuración estructural en abanico invertido, con pliegues y cabalgamientos orientados norte-sur, mucho más apretados en la mitad septentrional y más laxos en la meridional, condiciona sensiblemente tanto la morfología y distribución de los sectores acuíferos tectónicos e hidrodinámicos, como el trazado de los ríos. Estos últimos discurren paralelos a las grandes estructuras en la mitad sur, mientras que en la mitad norte se encajan en las áreas de debilidad estructural que originan las zonas de transferencia tectónica, atraviesan perpendicularmente los afloramientos mesozoicos y establecen marcadas relaciones río-acuífero.

En el bloque septentrional, al norte del río Gigüela, los sectores acuíferos 1 a 7 definidos según el análisis estructural serían prácticamente equivalentes a los sectores hidrodinámicos 1 a 6 definidos por piezometría (figura 12).

En el bloque meridional, los límites trazados en sentido norte-sur entre los sectores $8,9,10$ y 11 de la sectorización tectónica son coincidentes con los establecidos entre los sectores 7, 8, 10 y 11 de la sectorización hidrodinámica. En todos los casos, estos límites actúan como barreras al flujo subterráneo.

Sin embargo, los límites en sentido este-oeste, establecidos en la sectorización tectónica a partir de las zonas de transferencia, no tienen su equivalente en la sectorización hidrodinámica. Así, por ejemplo, el

\begin{tabular}{|c|c|c|c|c|c|c|c|c|c|c|}
\hline \multirow{2}{*}{ Bloppe } & \multicolumn{4}{|c|}{ Sectores zuiferem } & \multicolumn{3}{|c|}{ Red hidrografica } & \multicolumn{3}{|c|}{ Relación nio-acuifero } \\
\hline & Hidrextaninisicon & Tectánicon & Abrologia & Carasteribitica hildrogeoligicica & Cance & Orientasión & Crarateribiticas & Casce & Tipo & Carrateribiticas \\
\hline \multirow{8}{*}{ Nerte } & ' & 1 & \multirow{8}{*}{ 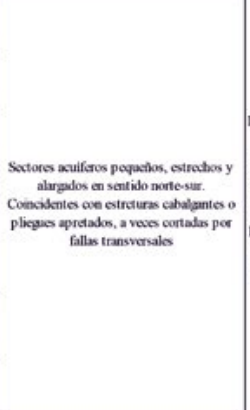 } & \multirow{8}{*}{ 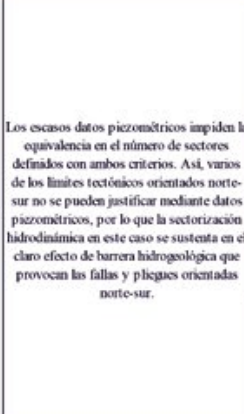 } & \multirow{2}{*}{ Rimuses: } & \multirow{8}{*}{ NESO } & \multirow{8}{*}{ 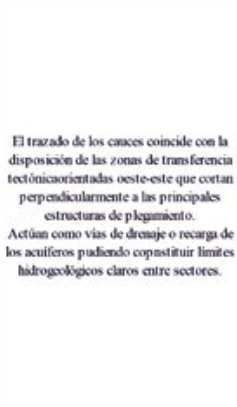 } & \multirow{2}{*}{ Rimansors } & \multirow{8}{*}{ varialk } & \multirow{8}{*}{ 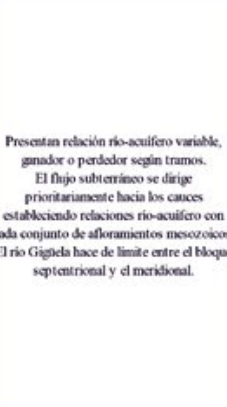 } \\
\hline & 2 & 2 & & & & & & & & \\
\hline & 3 & 3 & & & Basta & & & & & \\
\hline & & & & & & & & Bastip & & \\
\hline & & & & & cinect & & & & & \\
\hline & 5 & 5 & & & & & & \multirow{3}{*}{ Ginech } & & \\
\hline & 6 & 6 & & & \multirow{2}{*}{ vilumate } & & & & & \\
\hline & & 7 & & & & & & & & \\
\hline \multirow{8}{*}{ sur } & , & 8 & \multirow{8}{*}{ 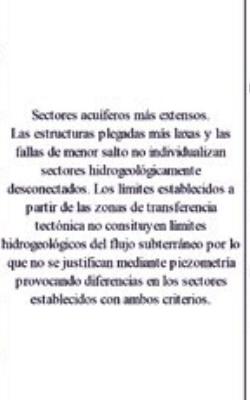 } & \multirow{8}{*}{ 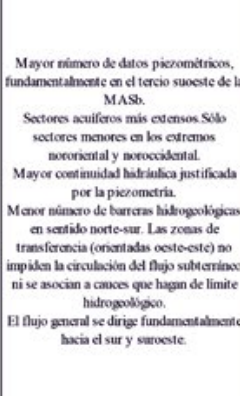 } & \multirow{3}{*}{ Tousar-sone } & \multirow{8}{*}{ N.s } & & \multirow{2}{*}{ vilunare } & \multirow{6}{*}{ Inthlosere } & \multirow{8}{*}{ 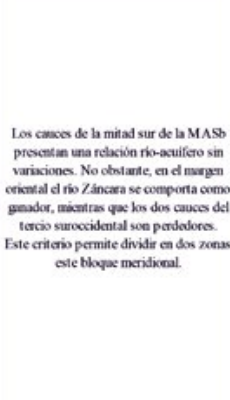 } \\
\hline & 8 & 9 & & & & & & & & \\
\hline & g & 10 & & & & & & \multirow{4}{*}{ Troman-some } & & \\
\hline & & & & & \multirow{5}{*}{ Zimana } & & 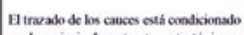 & & & \\
\hline & 10 & $n$ & & & & & 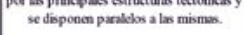 & & & \\
\hline & \multirow[t]{3}{*}{11} & 12 & & & & & & & & \\
\hline & & 13 & & & & & & \multirow{2}{*}{ 7tancern } & \multirow{2}{*}{ Emante } & \\
\hline & & 14 & & & & & & & & \\
\hline
\end{tabular}

Tabla 8. Correlación entre las distintas sectorizaciones establecidas en la MASb Sierra de Altomira.

Table 8. Correlation between the different sectorizations established in the Sierra de Altomira GWB. 

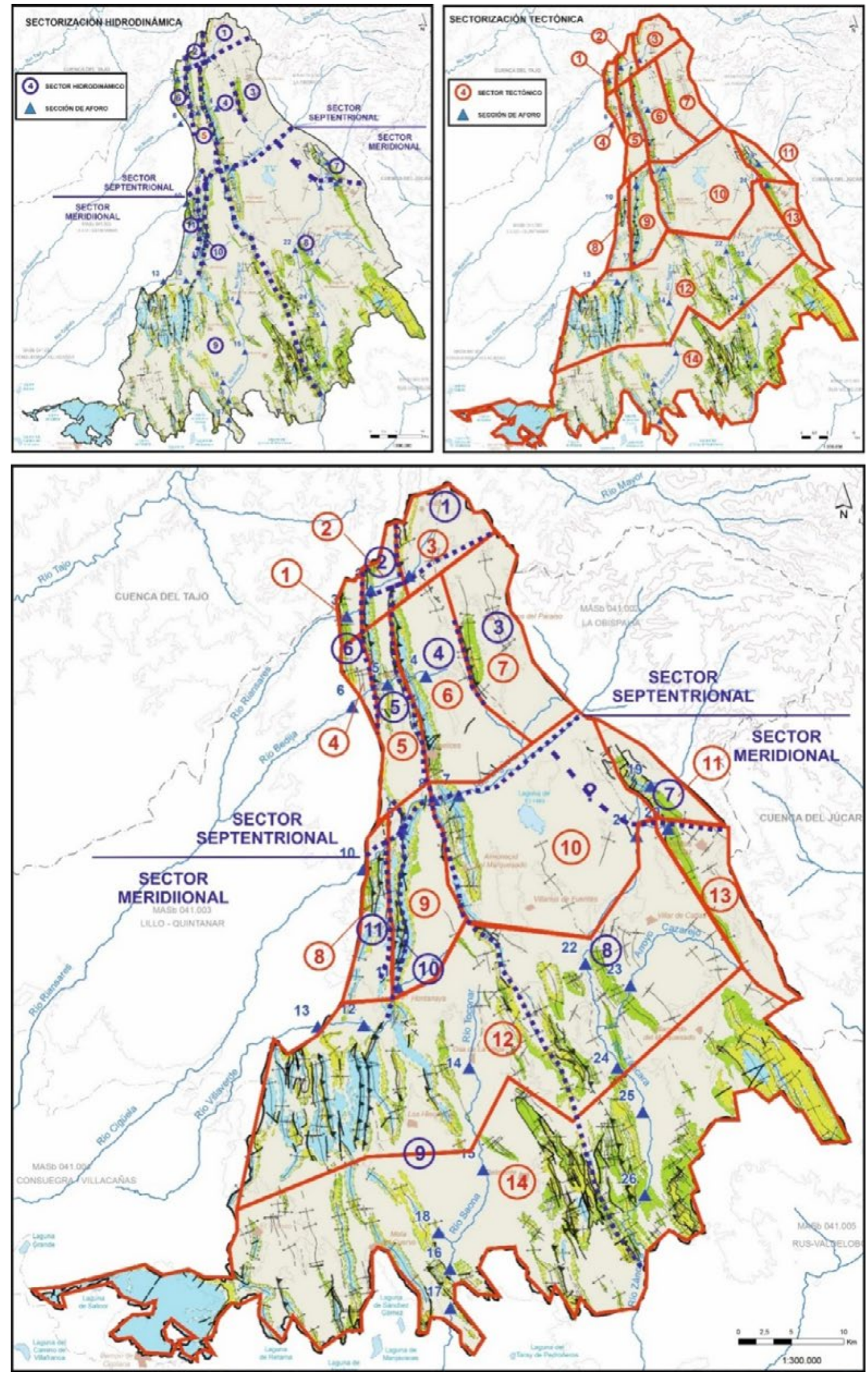

Figura 12. Comparativa entre las sectorizaciones hidrodinámica y tectónica. Figure 12. Comparison between hydrodynamic and tectonic sectorizations. 
límite tectónico trazado a partir de la falla Hontanaya-Villares del Saz (figura 8), constituye una zona de transferencia hidrogeológica que ha servido para trazar una divisoria según este criterio de sectorización, pero que, tal como indican los datos piezométricos no actúa como barrera, puesto que existe continuidad hidráulica. Es decir, el límite establecido en la sectorización tectónica entre los sectores acuíferos 8,9 y 10 con el sector 12, no tiene equivalente en la sectorización hidrodinámica, donde únicamente se ha definido una posible barrera hidráulica entre el sector 7 y 8 , que, en este caso, sí tendría su homólogo en el límite entre los sectores 11 y 13 de la sectorización tectónica.

Lo mismo sucede con el límite establecido en la sectorización tectónica entre los sectores acuíferos 12 y 14 (figura 9) a partir de la denominada zona de transferencia Toboso-Montalbanejo (figura 8). En este sector no se puede fijar ningún límite por piezometría (figura 6) ya que la interpretación realizada de la hidrodinámica, tanto del acuífero jurásico (figura 4) como del cretácico (figura 5), establece que hay continuidad hidráulica en todo el tercio suroccidental de la MASb, desde Almonacid del Marquesado, en el centro de la MASb, hasta Campo de Criptana, en su extremo suroeste, con un flujo subterráneo continuo hacia el sur y suroeste.

En este bloque sur, los ríos no aprovechan dichas zonas de transferencia para establecer su trazado, sino que se orientan paralelos a las estructuras de plegamiento, en lugar de atravesarlas $y$, al contrario que el río Gigüela, no constituyen límites entre sectores acuíferos.

\section{Propuesta de sectorización}

Tras el análisis anterior se propone la división de la MASb Sierra de Altomira en 4 sectores acuíferos con el objetivo es hacer más eficiente la gestión del conjunto de sus recursos hídricos subterráneos: sector acuífero de Carrascosa del Campo; sector acuífero de Uclés; sector acuífero de Villar de Cañas y sector acuífero de Mota del Cuervo (figura 13 y tabla 9).

Esta compartimentación implica obviar que en cada sector pueden coexistir en la vertical varios niveles permeables diferentes (niveles jurásicos, cretácicos y terciarios) y/o incluir varios acuíferos o subsectores acuíferos desconectados. Es decir, se realiza una simplificación que facilita la gestión de cada sector al considerar la totalidad de los recursos hídricos subterráneos del mismo sin distribuirlos por niveles acuíferos o tener en consideración subsectores acuíferos menores, excesivamente reducidos. Al subdividir la MASb en cuatro contextos hidrogeológicos de menor extensión, entre 140 y $1200 \mathrm{~km}^{2}$, e independientes, se busca que resulte más sencillo ajustar los parámetros de los balances hídricos respectivos.

Los sectores así establecidos son:

Sector acuífero de Carrascosa del Campo: ocupa unos $302 \mathrm{~km}^{2}$ en el sector nororiental de la
MASb. Sus límites norte y este coinciden con los actuales límites de la MASb Sierra de Altomira. Incluye las cabeceras de los ríos Riansares, Bedija y Gigüela. Este último cauce marca su límite meridional. Su margen occidental, entre Vellisca, al norte, y Saelices, al sur, queda definido por las estructuras cabalgantes y las alineaciones de pliegues anticlinales que aproximan a la superficie materiales impermeables de la facies Keuper, que actúan como barreras del flujo subterráneo. La piezometría de este sector ronda los $840 \mathrm{~m}$ s.n.m. en el acuífero jurásico y los $820 \mathrm{~m}$ s.n.m. en el cretácico y el flujo subterráneo general tiene dirección suroeste, hacia el río Gigüela.

- Sector acuífero de Uclés: es el sector acuífero más pequeño diferenciado, con aproximadamente $140 \mathrm{~km}^{2}$ de extensión. Se sitúa al oeste del anterior, por lo que ocupa el vértice noroccidental de la MASb. Se trata de una franja de terreno de unos $5,4 \mathrm{~km}$ de ancho por unos 26 $\mathrm{km}$ de largo, que se extiende desde el norte del río Riansares hasta el río Gigüela. Los márgenes occidental y septentrional coinciden con los propios de la MASb. El límite sur lo marca, como en el caso anterior, el río Gigüela y el oriental, la mencionada alineación de estructuras que constituyen una barrera cerrada al flujo subterráneo con el sector acuífero de Carrascosa del Campo. En este sector acuífero se suceden estructuras cabalgantes orientadas $\mathrm{N}-\mathrm{S}$ que hacen aflorar consecutivamente materiales del Jurásico y del Cretácico, por lo que coexisten acuíferos independientes, con diferente piezometría. La interpretación hidrodinámica indica que el flujo subterráneo en la mitad norte se dirige desde el margen oriental, a cotas superiores a los $885 \mathrm{~m}$ s.n.m. (nivel piezométrico del acuífero jurásico), hacia el noroeste, hacia el río Riansares, en su tramo final antes de salir de la MASb, donde es ganador, en torno a la cota 800-810 m s.n.m. En esta zona, probablemente, también se producen transferencias a la cuenca delTajo. En la mitad sur, por el contrario, el flujo se dirige hacia el río Gigüela y la MASb 041.003 Lillo-Quintanar, es decir, hacia el sur y suroeste. - Sector acuífero de Villar de Cañas: se sitúa al sureste del río Gigüela, en el margen suroriental de la MASb Sierra de Altomira. Con unos $933 \mathrm{~km}^{2}$ incluye la práctica totalidad de la cuenca del río Záncara. Su límite oriental y sur coincide con los propios de la MASb. El septentrional lo marca el río Gigüela, que establece la frontera con el acuífero de Carrascosa del Campo. Finalmente, el margen occidental, que limita con el sector acuífero de Mota del Cuervo, se ha trazado siguiendo la alineación de cabalgamientos y pliegues que se desarrolla desde Almonacid del Marquesado, al norte, hasta el punto más meridional en el que 

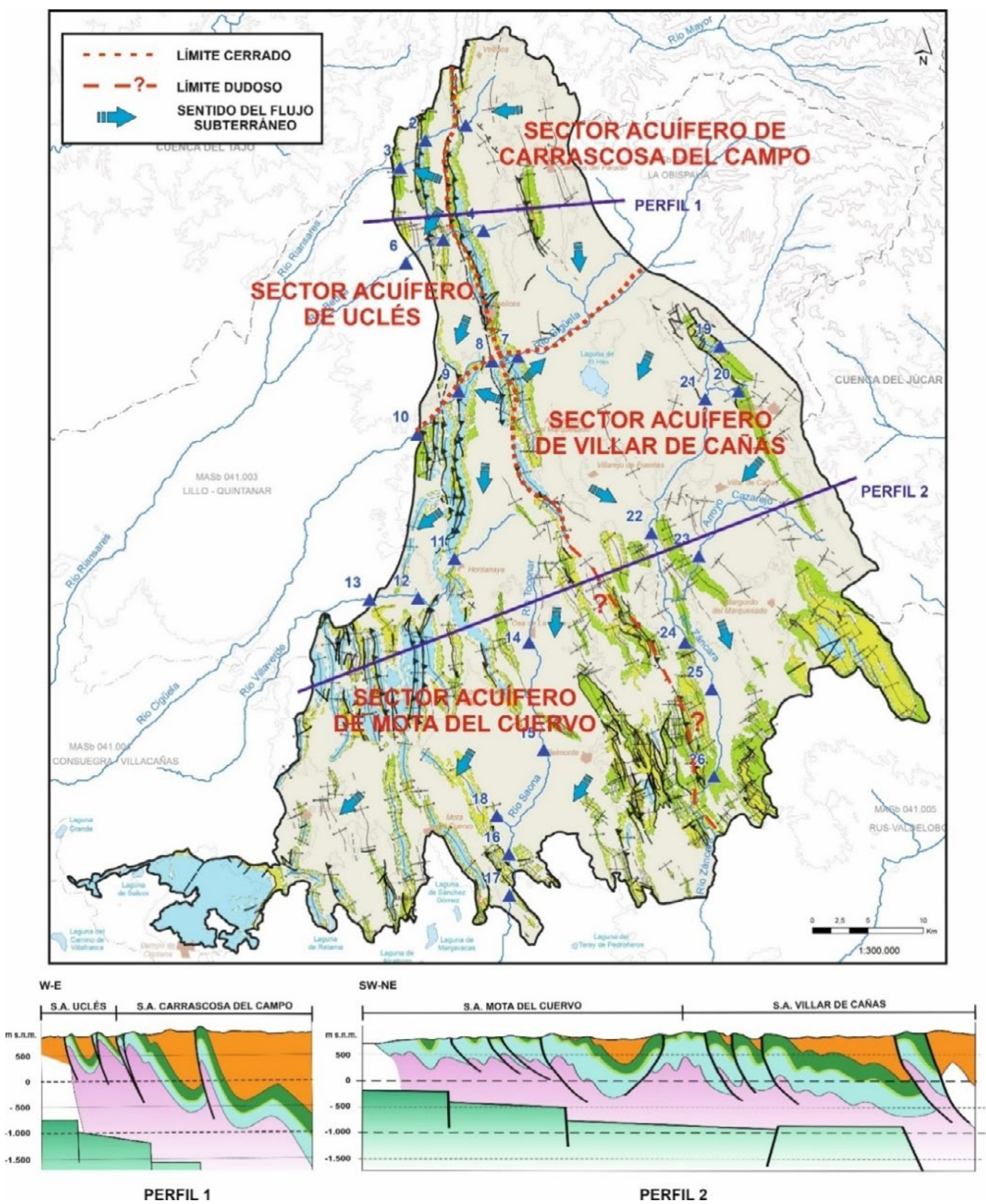

Figura 13. Sectorización resultante de la MASb Sierra de Altomira. Modificado de Domínguez et al., 2018 b y del Pozo et al., 2019. Figure 13. Final sectorization of the Sierra de Altomira GWB. Modified from Domínguez et al., 2018 b and del Pozo et al., 2019. 


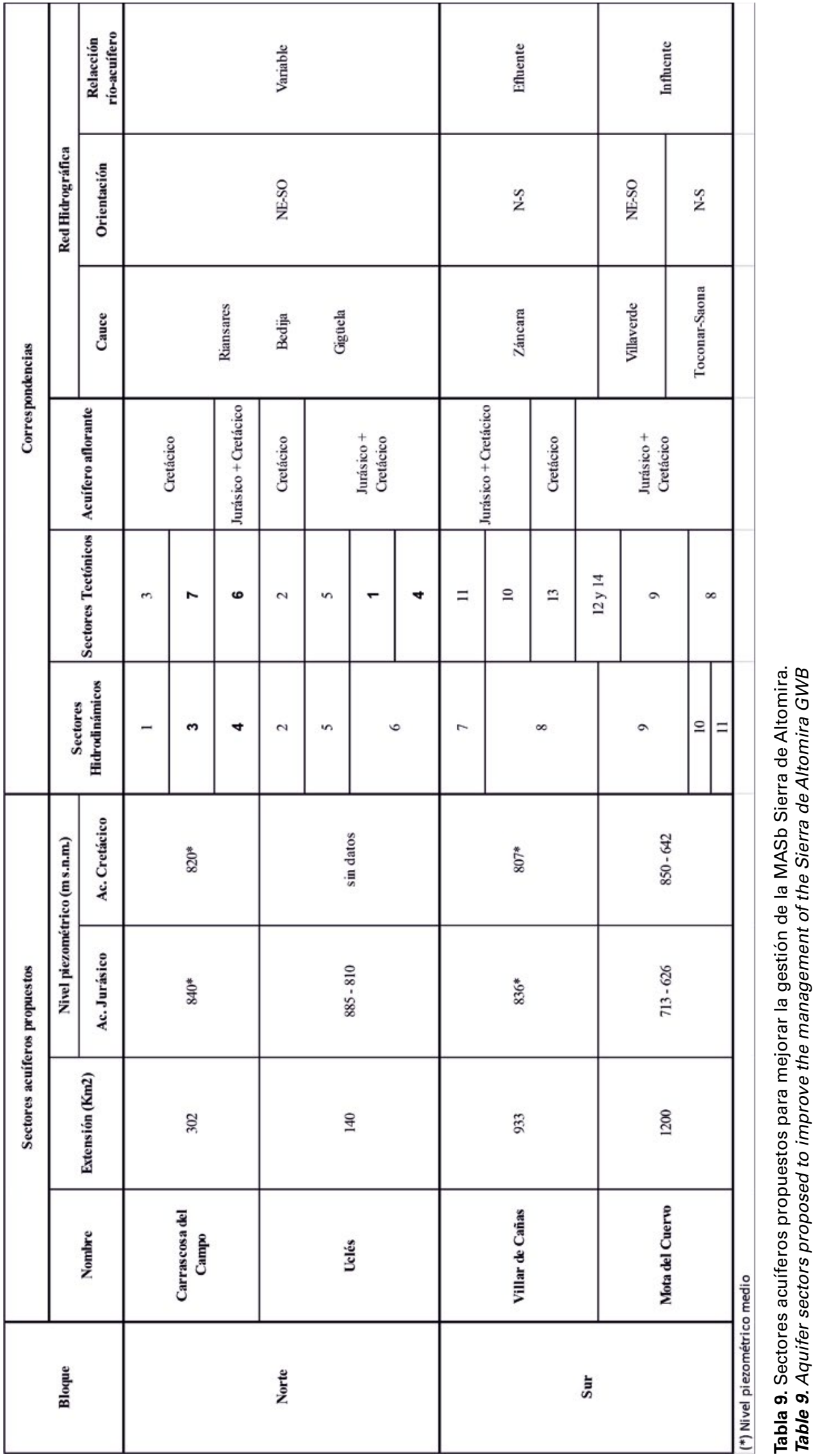


el río Záncara abandona la MASb. Este límite se considera cerrado en su mitad septentrional, mientras que constituye un umbral piezométrico en su mitad sur, donde los pliegues generan un anticlinorio que obliga al flujo subterráneo a tener sentidos ligeramente distintos a ambos lados del mismo, manteniendo, eso sí, una componente principal hacia el sur. Desde este sector se producen importantes transferencias hacia la vecina MASb 041.005 Rus-Valdelobos. La cota piezométrica media del acuífero jurásico se sitúa en torno de los 836 m s.n.m., mientras que en el acuífero cretácico se fija sobre los 807 m s.n.m.

Sector acuífero de Mota del Cuervo: ocupa unos $1200 \mathrm{~km}^{2}$ del margen suroccidental de la MASb Sierra de Altomira, en un triángulo con vértice norte en el río Gigüela a la altura de Saelices, y los vértices basales en Campo de Criptana, al oeste y Las Pedroñeras, al este. Incluye así las cuencas altas de los ríos Villaverde y Toconar-Saona.

En todo este amplio sector, pese a la presencia de algunas estructuras con orientación N-S que pueden actuar como semibarreras hidrogeológicas y que afectan especialmente a los niveles permeables del Cretácico, e individualizan pequeños acuíferos de uso local, se asume que el flujo subterráneo general discurre ininterrumpidamente con dirección suroeste, hacia las MASb vecinas 041.004 Consuegra-Villacañas y 041.006 Mancha Occidental II. La piezometría no sufre saltos significativos. En el acuífero Jurásico varía entre $713 \mathrm{~m}$ s.n.m. en el extremo noreste y los $626 \mathrm{~m}$ s.n.m. del vértice suroccidental, en el entorno de Campo de Criptana, donde únicamente existe este acuífero. Por su parte, la piezometría del acuífero cretácico oscila entre los $850 \mathrm{~m}$ s.n.m. del margen nororiental y los 642 m s.n.m. medidos al sur de ElToboso.

\section{Conclusiones}

En el presente estudio se comparan y correlacionan dos sectorizaciones hidrogeológicas de la MASb Sierra de Altomira, una establecida al aplicar criterios hidrodinámicos y otra criterios estructurales.

Por un lado, a partir de los resultados de campañas de piezometría realizadas entre 2012 y 2018 se han definido unos límites que separan ámbitos dentro de la MASb con hidrodinámicas distintas, estableciendo así una sectorización "hidrodinámica".

Por otra parte, un análisis estructural de la MASb permite establecer sus Unidades Hidrogeológicas Básicas (UHB), o unidades estructurales mínimas divisibles con funcionamiento hidrogeológico individualizado. La identificación, dentro de la MASb Sierra de Altomira, de las UHB con límites este-oeste cerrados al flujo subterráneo ha constituido la base para establecer una sectorización "tectónica".

Ambas sectorizaciones se han comparado entre sí, y se han correlacionados con sectorizaciones basadas en el trazado de los cursos fluviales y en las relaciones río-acuífero, comprobando que gran número de los límites entre los sectores establecidos con unos y otros criterios eran coincidentes.

Finalmente, a partir de la combinación de las sectorizaciones tectónica e hidrodinámica y con el objetivo de mejorar la gestión de los recursos hídricos subterráneos de la MASb, se ha dividido esta en cuatro sectores acuíferos (Carrascosa del Campo; Uclés; Villar de Cañas y Mota del Cuervo).

Dichos sectores pueden incluir tramos permeables diferentes y/o acuíferos menores que pueden estar desconectados, pero se simplificaría la gestión al poder establecer balances hídricos independientes de entornos hidrogeológicos de límites bien definidos y menos extensos (entre 140 y $1200 \mathrm{~km}^{2}$ ).

\section{Agradecimientos}

Los autores agradecen la inestimable ayuda ofrecida tanto por la Comunidad de Usuarios de Aguas Subterráneas de Sierra de Altomira, encabezados por su presidente, D. Rafael Rodrigo Medina como la de los ayuntamientos y empresas de gestión de aguas municipales incluidos en la MASb. Todos ellos han facilitado importante información y han permitido ampliar la red de control hidrogeológico establecida para este estudio al permitir el acceso a puntos de observación distintos de los incluidos en la red oficial de la Cuenca Hidrográfica del Guadiana.

\section{Referencias bibliografía}

Confederación Hidrográfica del Guadiana (2007). Plan Hidrológico de la parte española de la Demarcación Hidrográfica del Guadiana (2009-2015)

Del Pozo Tejado, J., Mejías Moreno, M. and Domínguez Sánchez, J.A. 2019. Propuesta de compartimentación estructural en la MASb 041.001 Sierra de Altomira: implicaciones hidrogeológicas. Boletín Geológico y Minero, 120 (3): 459-479. Madrid.

Díaz Muñoz, J.A. and Martínez Parra, M. 2009. Mejora del conocimiento de las MASb Sierra de Altomira (041.001) y Rus-Valdelobos (041.005). Convenio de colaboración entre el Instituto Geológico y Minero de España (IGME) y la Confederación Hidrográfica del Guadiana (CHG). Documento inédito. Centro de Documentación del IGME. Madrid. 187 pp + 14 mapas.

Díaz Muñoz, J.A., Martínez Parra, M. and de la Losa Román, A. 2011. Actualización del conocimiento hidrogeológico de la masa de agua subterránea "Sierra de Altomira (041.001)." Convenio de colaboración entre la Excma. Diputación de Cuenca y el Instituto Geológico y Minero de España para la mejora del conocimiento hidrogeológico. Madrid. 127 pp. y anejos.

Directiva 2000/60/CE del Parlamento Europeo y del 
Consejo de 23 de octubre de 2000 por la que se establece un marco comunitario de actuación en el ámbito de la política de aguas.

Domínguez Sánchez, J.A., Ruíz Hernández, J.M., Mejías Moreno, M., Vega Martín, L., Gómez-Escalonilla Sánchez, M.D. and Ochando Jiménez, R. 2014. EI balance hídrico como elemento esencial en la gestión de los recursos hídricos subterráneos. El caso de la MASb Sierra de Altomira. II Congreso Ibérico de la Aguas Subterráneas, CIAS2014. Valencia 8-10 de septiembre de 2014.

Domínguez Sánchez, J.A., Mejías Moreno, M., Vega Martín, L., Gómez-Escalonilla Sánchez, M.D., Del Pozo Tejado, J. and Ochando Jiménez, R. 2016. "Estudio de la evolución piezométrica de la masa de agua subterránea Sierra de Altomira (041.001). Informe recopilatorio 1982-2015. Convenio específico de colaboración entre la Comunidad de Regantes de Aguas Subterráneas de la Sierra de Altomira y el IGME, para el apoyo técnico en infraestructura hidrogeológica y aguas subterráneas. 2012-2015 Documento interno.

Domínguez Sánchez, J.A., Mejías Moreno, M., Vega Martín, L., Del Pozo Tejado, J. and Ochando Jiménez, R. 2018 a. Estudio piezométrico. Campañas de medida 2018 en la MASb "Sierra de Altomira (041.001)" Convenio específico de colaboración entre la Comunidad de Regantes de Aguas Subterráneas de la Sierra de Altomira y el IGME, para el apoyo técnico en infraestructura hidrogeológica y aguas subterráneas. 2016-2018. Documento interno.

Domínguez Sánchez, J.A., Mejías Moreno, M., Vega Martín, L., Del Pozo Tejado, J. and Ochando Jiménez, R. 2018 b. Estudio foronómico. Campañas de medida 2018 en la MASb "Sierra de Altomira (041.001)". Convenio específico de colaboración entre la Comunidad de Regantes de Aguas Subterráneas de la Sierra de Altomira y el IGME, para el apoyo técnico en infraestructura hidrogeológica y aguas subterráneas. 2016-2018. Documento interno.

Galindo Rodríguez, M.E., Gómez-Escalonilla Sánchez, M.D., González Fernández, M.I. and Mejías Moreno, M. (2012). "Informe de evolución piezométrica de la masa de agua subterránea Sierra de Altomira (041.001). Años 1982-2012. Diciembre de 2012". Convenio específico de colaboración entre la Comunidad de Regantes de Aguas Subterráneas de la Sierra de Altomira y el IGME, para el apoyo técnico en infraestructura hidrogeológica y aguas subterráneas. 2012-2015 Documento interno.

Guimerá, J. 2004. Cadenas con cobertera: las cadenas Ibérica y Costero Catalana. En Vera, J.A. (ed.), Geología de España, Sociedad Geológica de España e Instituto Geológico y Minero de España, Madrid, 602-616.

IGME. 1979. Plan Nacional de Investigación de Aguas Subterráneas (PNIAS): Proyecto de investigación hidrogeológica de la cuenca alta del Guadiana. Informe final (Sistema 19: Sierra de Altomira. Sistema 20: de la Mancha de Toledo. Sistema 22: Cuenca del río Bullaque. Sistema 23: Llanura Manchega. Sistema 24: Campo de Montiel.Centro de Documentación del IGME, Madrid, 119 págs. +3 planos.

IGME-MOPU. 1988. Delimitación de las Unidades Hidrogeológicas del territorio peninsular e islas Baleares y síntesis de sus características. Cuenca del Guadiana.

Martínez Cortina, L. Mejías Moreno, M., Díaz Muñoz, J.A., Morales García, R. and Ruíz Hernández, J.M., 2011. Cuantificación de recursos hídricos subterráneos en la cuenca alta del Guadiana. Consideraciones respecto a las definiciones de recursos renovables y disponibles. Boletín Geológico y Minero, 122 (1): 17-36.

Martínez Parra, M. and Díaz Muñoz, J.A. 2013. Propuesta de zonificación hidrogeológica de las masas de agua subterránea (041.001) Sierra de Altomira y (041.005) Rus-Valdelobos. Boletín Geológico y Minero. 124 (3): 351-365

Mejías Moreno, M., 2014. El agua protagonista a través de los siglos. En: Mejías Moreno, M. (ed.). Las Tablas y Los Ojos del Guadiana: agua, paisaje y gente. IGME-OAPN, Madrid: 15-64.

Mejías Moreno, M., Ruíz Hernández, J.M., Domínguez Sánchez J.A., Casas Ruíz, S., García Pardo, B., Delgado Pastor, J. and Padilla Benítez, A. 2014. "Estimación del balance hídrico de la masa de agua subterránea Sierra de Altomira (041.001)". Convenio específico de colaboración entre la Comunidad de Regantes de Aguas Subterráneas de la Sierra de Altomira y el IGME, para el apoyo técnico en infraestructura hidrogeológica y aguas subterráneas. 2012-2015. Documento interno.

Muñoz Martín, A. 1997. Evolución geodinámica del borde oriental de la cuenca del Tajo desde el Oligoceno hasta la actualidad. Tesis Doctoral Universidad Complutense de Madrid. Madrid, 331 pp. y anejos.

Muñoz Martín, A, and De Vicente, G., 1998. Cuantificación del acortamiento alpino y estructura en profundidad del extremo sur-occidental de la Cordillera lbérica (Sierras de Altomira y Bascuñana). Revista Sociedad Geológica de España, 11(3-4), 233-252.

Murillo Díaz, J.M., Azcón González, A., Ballesteros Navarro, B., Aragón Rueda, R., Meléndez Asensio, M., Ruiz Hernández, J.M ${ }^{a}$, Martínez Cortina, L., López Gutiérrez, J.C. and Rubio Campos, J.C. 2010. Actividad 4: Identificación y caracterización de la interrelación que se presenta entre aguas subterráneas, cursos fluviales, descargas por manantiales, zonas húmedas y otros ecosistemas naturales de especial interés hídrico Demarcación Hidrográfica 040 Guadiana Masa de agua subterránea 040.001 Sierra de Altomira. Encomienda de gestión para la realización de trabajos científico-técnicos de apoyo 
a la sostenibilidad y protección de las aguas subterráneas.

Sánchez Soria, P. 1973. Estudio geológico de la Sierra de Altomira (entre Paredes y Belmonte). Tesis doctoral Univ. Complutense de Madrid. Madrid, 297 pp. Winter, T.C. 1995. Recent advances in understanding the interaction of groundwater and surface water. Reviews of Geophysics (Suppl):985-994.

Winter, T.C., Harvey, J.W., Franke, O.L. and Alley, W.M. 1998. Ground water and surface water: A single resource. US Geological Survey Numbered Series. Circular 1139.

Recibido: julio 2019

Revisado: noviembre 2019

Aceptado: enero 2020

Publicado: diciembre 2021 